\title{
Guidelines for Diagnosis and Treatment of Primary Liver Cancer in China (2017 Edition)
}

\author{
Jian Zhou ${ }^{a} \quad H u i-C h u a n$ Sun ${ }^{a}$ Zheng Wang ${ }^{a}$ Wen-Ming Cong ${ }^{b}$ Jian-Hua Wang ${ }^{c}$ \\ Meng-Su Zeng ${ }^{d}$ Jia-Mei Yang ${ }^{e}$ Ping Bie $^{f}$ Lian-Xin Liug $^{g}$ Tian-Fu Wen ${ }^{\text {h }}$

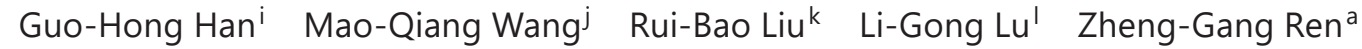 \\ Min-Shan Chen ${ }^{m}$ Zhao-Chong Zeng ${ }^{n}$ Ping Liang ${ }^{\circ}$ Chang-Hong Liang ${ }^{p}$ Min Chen ${ }^{q}$ \\ Fu-Hua Yan ${ }^{r}$ Wen-Ping Wang ${ }^{s}$ Yuan Ji ${ }^{t}$ Wen-Wu Cheng ${ }^{u}$ Chao-Liu Dai ${ }^{v}$ \\ Wei-Dong Jiaw Ya-Ming Li ${ }^{x}$ Ye-Xiong Li ${ }^{y}$ Jun Liang ${ }^{z}$ Tian-Shu Liu ${ }^{A}$ Guo-Yue Lv ${ }^{B}$ \\ Yi-Lei Mao ${ }^{C}$ Wei-Xin Ren ${ }^{D}$ Hong-Cheng Shi ${ }^{E}$ Wen-Tao Wang ${ }^{F}$ Xiao-Ying Wang ${ }^{\text {a }}$ \\ Bao-Cai Xing ${ }^{G}$ Jian-Ming $\mathrm{Xu}^{\mathrm{H}}$ Jian-Yong Yang' Ye-Fa Yang ${ }^{J}$ Sheng-Long $\mathrm{Ye}^{\mathrm{a}}$ \\ Zheng-Yu Yin ${ }^{\mathrm{K}}$ Bo-Heng Zhang ${ }^{\mathrm{a}}$ Shui-Jun Zhang ${ }^{\mathrm{L}}$ Wei-Ping Zhou ${ }^{\mathrm{e}}$ Ji-Ye Zhu ${ }^{\mathrm{M}}$ \\ Rong Liu ${ }^{c}$ Ying-Hong Shi ${ }^{a}$ Yong-Sheng Xiao ${ }^{a}$ Zhi Dai $^{a}$ Gao-Jun Teng ${ }^{N}$ \\ Jian-Qiang $\mathrm{Cai}^{\mathrm{O}}$ Wei-Lin Wang ${ }^{\mathrm{P}}$ Jia-Hong Dong ${ }^{\mathrm{Q}}$ Qiang $\mathrm{Li}^{\mathrm{R}}$ Feng Shen ${ }^{\mathrm{e}}$ \\ Shu-Kui Qin ${ }^{\mathrm{S}}$ Jia Fan ${ }^{\mathrm{a}}$
}

\begin{abstract}
a Department of Liver Surgery \& Transplantation, Liver Cancer Institute, Zhongshan Hospital, Fudan University, Key Laboratory of Carcinogenesis and Cancer Invasion, Ministry of Education, Fudan University, Shanghai, China; ${ }^{b}$ Department of Pathology, the Eastern Hepatobiliary Surgery Hospital, Second Military Medical University, Shanghai, China; ' ${ }^{c}$ Department of Interventional Radiology, Zhongshan Hospital, Fudan University, Shanghai, China; ${ }^{\mathrm{d} D e p a r t m e n t ~ o f ~ R a d i o l o g y, ~}$ Zhongshan Hospital, Fudan University, Shanghai, China; e Department of Hepatic Surgery, the Eastern Hepatobiliary Surgery Hospital, Second Military Medical University, Shanghai, China; ${ }^{f}$ Institute of Hepatobiliary Surgery, Southwest Hospital, Third Military Medical University, Chongqing, China; gDepartment of General Surgery, the First Affiliated Hospital of Harbin Medical University, Harbin, China; ${ }^{h}$ Department of Liver Surgery, West China Hospital of Sichuan University, Chengdu, China; 'Department of Liver Diseases and Digestive Interventional Radiology, Xijing Hospital, Fourth Military Medical University, Xi'an, China; 'Department of Interventional Radiology, Chinese PLA General Hospital, Beijing, China; ${ }^{k}$ Department of Interventional Radiology, the Tumor Hospital of Harbin Medical University, Harbin, China; 'Department of Interventional Oncology, Guangdong General Hospital, Guangdong Academy of Medical Sciences, Guangzhou, China; ${ }^{m}$ Department of Hepatobiliary Surgery, Sun Yat-sen University Cancer Center, Guangzhou, China; ${ }^{n}$ Department of Radiation Oncology, Zhongshan Hospital, Fudan University, Shanghai, China; ${ }^{\circ}$ Department of Interventional Ultrasound, Chinese PLA General Hospital, Beijing, China; ${ }^{\mathrm{p}}$ Department of Radiology, Guangdong General Hospital, Guangdong Academy of Medical Sciences, Guangzhou, China; qEditorial Department of Chinese Journal of Digestive Surgery, Chongqing, China; 'Department of Radiology, Ruijin Hospital Affiliated to Shanghai Jiaotong University School of Medicine, Shanghai,

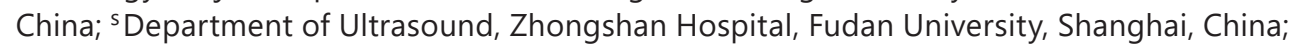
${ }^{t}$ Department of Pathology, Zhongshan Hospital, Fudan University, Shanghai, China; "Department of integrated treatment, Tumor Hospital of Fudan University, Shanghai, China;
\end{abstract}

Jian Zhou, Hui-Chuan Sun, and Zheng Wang contributed equally to this study.

Dr. Jia Fan

Department of Liver Surgery \& Transplantation, Liver Cancer Institute, Zhongshan Hospital, Fudan University

180 Fenglin Road, Shanghai 200032 (China)

E-Mail fan.jia@zs-hospital.sh.cn
Dr. Shu-Kui Qin

Department of Medical Oncology, PLA Cancer Center Nanjing Bayi Hospital

Nanjing 210002 (China)

E-Mail qinsk@csco.org.cn 


\title{
Liver Cancer
}

\begin{tabular}{|c|c|}
\hline \multicolumn{2}{|l|}{ Liver Cancer 2018;7:235-260 } \\
\hline DOI: 10.1159/000488035 & $\begin{array}{l}\text { (c) } 2018 \text { S. Karger AG, Basel } \\
\text { www.karger.com/lic }\end{array}$ \\
\hline
\end{tabular}

Zhou et al.: 2017 Liver Cancer Guidelines in China

vDepartment of Hepatobiliary and Spleenary Surgery, the Affiliated Shengjing Hospital, China

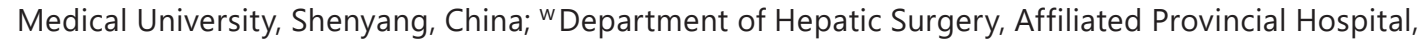
Anhui Medical University, Hefei, China; ${ }^{x}$ Department of Nuclear Medicine, the First Hospital of

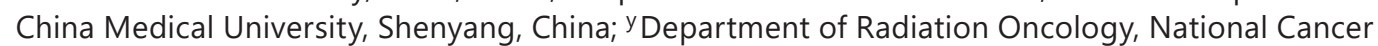
Center/Cancer Hospital, Chinese Academy of Medical Sciences and Peking Union Medical College, Beijing, China; ${ }^{2}$ Department of Oncology, Peking University International Hospital, Beijing, China; A Department of Oncology, Zhongshan Hospital, Fudan University, Shanghai, China; ${ }^{B}$ Department of General Surgery, the First Hospital of Jilin University, Jilin, China; ${ }^{C}$ Department of Liver Surgery, Peking Union Medical College (PUMC) Hospital, PUMC and Chinese Academy of Medical Sciences, Beijing, China; Department of Interventional Radiology, the First Affiliated Hospital of Xinjiang Medical University, Urumqi, China; EDepartment of Nuclear Medicine, Zhongshan Hospital, Fudan University, Shanghai, China; ${ }^{\mathrm{F}}$ Department of Liver Surgery, West China Hospital of Sichuan University, Chengdu, China; ${ }^{G}$ Department of Hepato-Pancreato-Biliary Surgery, Peking University Cancer Hospital and Institute, Beijing, China; ${ }^{H}$ Department of Gastrointestinal Oncology, Affiliated Hospital Cancer Center, Academy of Military Medical Sciences, Beijing, China; 'Department of Interventional Oncology, the First Affiliated Hospital, Sun Yat-sen University, Guangzhou, China; 'Department of Hepatic Surgery and Interventional Radiology, Eastern Hepatobiliary Surgery Hospital, Second Military Medical University, Shanghai, China; ${ }^{K}$ Department of Hepatobiliary Surgery, Zhongshan Hospital of Xiamen University, Xiamen, China; 'Department of Hepatobiliary and Pancreatic Surgery, the First Affiliated Hospital of Zhengzhou University, Zhengzhou, China; M Department of Hepatobiliary Surgery, Peking University People's Hospital, Beijing, China; ${ }^{N}$ Department of Radiology, Zhongda Hospital, Medical School, Southeast University, Nanjing, China; ${ }^{\circ}$ Department of Abdominal Surgical Oncology, Cancer Hospital, Chinese Academy of Medical Sciences and Peking Union Medical

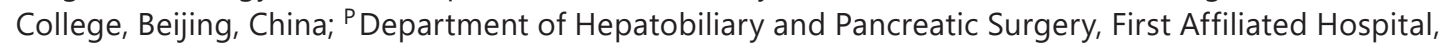
School of Medicine, Zhejiang University, Hangzhou, China; ${ }^{Q}$ Department of Hepatobiliary and Pancreas Surgery, Beijing Tsinghua Changgung Hospital (BTCH), School of Clinical Medicine, Tsinghua University, Beijing, China; ${ }^{R}$ Department of Hepatobiliary Surgery, Tianjin Medical University Cancer Institute and Hospital, Tianjin, China; ${ }^{S}$ Department of Medical Oncology, PLA Cancer Center, Nanjing Bayi Hospital, Nanjing, China

\section{Keywords}

Cancer $\cdot$ Carcinoma $\cdot$ China $\cdot$ Liver $\cdot$ Diagnosis $\cdot$ Treatment

\begin{abstract}
Background: Hepatocellular carcinoma (HCC) (about $85-90 \%$ of primary liver cancer) is particularly prevalent in China because of the high prevalence of chronic hepatitis B infection. $\mathrm{HCC}$ is the fourth most common malignancy and the third leading cause of tumor-related deaths in China. It poses a significant threat to the life and health of Chinese people. Summary: This guideline presents official recommendations of the National Health and Family Planning Commission of the People's Republic of China on the surveillance, diagnosis, staging, and treatment of HCC occurring in China. The guideline was written by more than 50 experts in the field of HCC in China (including liver surgeons, medical oncologists, hepatologists, interventional radiologists, and diagnostic radiologists) on the basis of recent evidence and expert opinions, balance of benefits and harms, cost-benefit strategies, and other clinical considerations. Key Messages: The guideline presents the Chinese staging system, and recommendations regarding patients with HCC in China to ensure optimum patient outcomes.
\end{abstract}




\section{Overview}

Primary liver cancer is the fourth most common malignancy and the third leading cause of tumor-related deaths in China; it poses a significant threat to the life and health of Chinese people [1,2]. Primary liver cancer is mainly divided into hepatocellular carcinoma (HCC), intrahepatic cholangiocarcinoma (ICC), and HCC-ICC according to pathological type. These three types vary greatly in pathogenesis, biological behaviors, histological morphology, treatment methods, and prognosis. HCC accounts for $85-90 \%$ of all cases of primary liver cancer. Therefore, the liver cancer described in these guidelines is HCC. The level of evidence in these guidelines was based on the Oxford Centre for Evidence-Based Medicine.

\section{Screening and Diagnosis}

\section{Monitoring and Screening of High-Risk Populations}

Screening of high-risk populations facilitates early detection, early diagnosis, and early treatment; therefore, it is critical for improving the outcome of liver cancer. In China, highrisk populations mainly comprise the following populations: populations with hepatitis $\mathrm{B}$ virus (HBV) and/or hepatitis C virus (HCV) infection, nonalcoholic fatty hepatitis, liver cirrhosis of all causes, a family history of liver cancer, and those with long-term alcohol abuse or those who consume aflatoxin-contaminated food. Men older than 40 years are at particularly increased risk. Alpha-fetoprotein (AFP) and liver ultrasonography are the main approaches for early screening. Monitoring every 6 months, at minimum, is recommended for high-risk populations [3].

\section{Imaging Examinations for Liver Cancer}

Imaging examinations have their own characteristics and are subject to the principle of integrated application, thus complementing each other's advantages and overall evaluation.

\section{Ultrasonography}

Abdominal ultrasonography is the most commonly used imaging examination for the liver due to its ease of use, flexibility, visualization, noninvasiveness, and convenience. Routine ultrasonography screening can sensitively detect suspected intrahepatic space-occupying lesions at an early stage, accurately differentiate cystic or space-occupying lesions, and observe the presence of other relevant metastatic lesions in the liver or abdomen. Color Doppler flow imaging not only visualizes the blood supply within the lesion but also identifies the adjacency relationship between the lesion and major vessels, which provides important information for the selection of treatment approaches and determination of a surgery plan. Contrast ultrasonography visualizes the hemodynamic changes within the liver cancer and facilitates the differentiation and diagnosis of different kinds of liver cancer [4]. This technique has advantages regarding the evaluation of microvascular perfusion and the guidance of interventional procedures for liver tumor because of its real-time multisection imaging.

Computed Tomography

Enhanced scans (with iodinated contrast agents) are commonly used. Their capability to detect and diagnose small liver tumor is slightly inferior to that of magnetic resonance imaging (MRI). This approach is more often used for the evaluation of the response of liver cancer to local treatment, particularly because of its ability to observe the deposition of iodized oil following transarterial chemoembolization (TACE), and because of its common application for the clinical diagnosis and staging of liver cancer. Furthermore, computed tomography 


\section{Liver Cancer}

Zhou et al.: 2017 Liver Cancer Guidelines in China

(CT) is widely used in clinical practice because of its three-dimensional (3D) measurements of liver volume and tumor volume and evaluations of metastasis to other organs such as the lungs and bones.

Magnetic Resonance Imaging

Plain and enhanced scans (commonly with Gd-DTPA contrast agents) are commonly used for the detection, diagnosis, and response of liver cancer in clinical practice due to a lack of irradiation, high tissue resolution, multidirectional and multiparameter imaging, morphology-combining features (including diffusion-weighted imaging, perfusion-weighted imaging, and spectrum analysis), and comprehensive imaging technique capabilities. The detection rate for $\leq 1.0-\mathrm{cm}$ liver cancer, diagnostic accuracy, and differential diagnoses of liver cancer are improved when used in combination with hepatocyte-specific contrast agents (Gd-EOB-DTPAs) [5-10].

Liver cancer exhibits obvious heterogeneous enhancement or, occasionally, obvious homogenous enhancement during the arterial phase (mainly during the late arterial phase) of MRI or CT. In particular, $\leq 5.0$-cm liver cancer exhibits reduced enhancement of the tumor in the portal venous phase and/or parenchyma balance phase scans. This enhancement mode of "rapid wash in and out" is characteristic of liver cancer $[11,12]$. The diagnosis of liver cancer by MRI and CT still requires the incorporation of other signs (e.g., pseudocapsule), particularly relevant signs shown in other sequences of MRI, for comprehensive judgment and consequently improved diagnostic accuracy.

Digital Subtraction Angiography

Digital subtraction angiography (DSA) is an invasive procedure. In most cases, it is recommended that it should be performed through the selective or ultraselective hepatic artery. This technique is more often used for the local treatment of liver cancer or for the treatment of acute bleeding from liver cancer rupture. Liver cancer mainly exhibits staining of the tumor blood vessels and tumors on DSA. DSA also helps identify the number, size, and blood supply of liver cancer and provides accurate and objective information regarding vascular anatomic variation and important vascular anatomic relationships as well as portal vein invasion by tumors, which has important value for judging the possibility and thoroughness of surgical resection and determining a proper treatment plan.

Nuclear Medical Imaging

Positron Emission Tomography/CT. The advantages of whole-body ${ }^{18} \mathrm{~F}$-fluorodeoxyglucose $\left({ }^{18} \mathrm{~F}-\mathrm{FDG}\right)$ positron emission tomography (PET)/CT are evident for the following: (1) tumor staging; (2) re-staging after treatment; (3) response evaluation; (4) guidance of biological target volume delineation for radiation therapy and puncture biopsy sites (evidence level 2) [13,14]; and (5) evaluation of the extent of malignancy and prognosis of the tumor (evidence level 2) [15-17]. During tumor staging, one procedure enables the overall evaluation of lymph node metastasis and distal organ metastasis (evidence level 1) [18, 19]. During re-staging, PET can accurately visualize changes in anatomic structures or tumor recurrence and metastases at the site with a complicated anatomic structure (evidence level 2) [13,14]. Regarding the response evaluation, PET is more sensitive and accurate for evaluating the response to molecular target drugs that act to inhibit tumor activity (evidence level 2) [20, 21]. PET/CT is beneficial for evaluating the extent of malignancy and the prognosis of tumors (evidence level 2) [15-17]. Carbon-11 acetate $\left({ }^{11} \mathrm{C}\right.$-acetate) and choline $\left({ }^{11} \mathrm{C}\right.$-choline) PET scans improve the diagnostic sensitivity for well-differentiated liver cancer and are complementary to ${ }^{18}$ F-FDG PET/CT. 
Single-Photon Emission CT. Single-photon emission CT (SPECT)/CT has become the mainstream device for nuclear medicine single-photon imaging. The lesions detected by wholebody planar imaging can be selected for local SPECT/CT fusion imaging, which significantly improves the accuracy of diagnosis by simultaneously obtaining the SPECT and diagnostic CT images of the lesions [22].

Liver Puncture Biopsy

Liver puncture biopsy is usually not necessary for patients with space-occupying lesions with typical imaging characteristics of liver cancer that are eligible for the clinical criteria for the diagnosis of liver cancer [23]. For space-occupying lesions without typical imaging characteristics of liver cancer, liver puncture biopsy provides pathological diagnosis and is very important for the diagnosis of liver cancer, guidance of treatment, and judgment of prognosis.

Liver puncture biopsy should be performed under the guidance of ultrasonography or CT. The histological diagnosis can be obtained using 18-gauge or 16-gauge core needle liver puncture biopsy, or cytological diagnosis can be obtained using fine-needle puncture. The major risk of liver puncture biopsy is bleeding or needle tract implantation. Therefore, platelet count and blood clotting should be preoperatively checked. Liver puncture biopsy is contraindicated in patients with serious hemorrhagic tendencies or serious diseases affecting the heart, lungs, brain, and kidneys or with systemic failure. To avoid the rupture of tumor nodules and needle tract implantation, normal liver tissues should be passed through using the puncture tract to avoid direct puncture of the nodules located on the surface of the liver. It is recommended that one piece of tissue each in the tumor and in the para-tumor liver tissue should be punctured for improved diagnostic accuracy based on objective comparison. The pathological diagnosis by liver puncture is associated with some false-negative results. The false negativity of biopsy is reported to be approximately 33\% [23]. Negative results cannot completely eliminate the possibility of liver cancer.

\section{Serological Molecular Markers for Liver Cancer}

AFP is a commonly used and important method of diagnosing liver cancer. Diagnostic criteria are AFP $\geq 400 \mu \mathrm{g} / \mathrm{L}$ and exclusion of chronic or active hepatitis, liver cirrhosis, embryonal tumor of the testis or ovary, and pregnancy. Patients with mildly increased AFP should be monitored in a dynamic manner. Changes in liver function should be considered and help facilitate the diagnosis. A normal AFP level is seen in approximately $30 \%$ of liver cancer patients, and AFP-L3 testing helps improve the diagnostic rate. Other molecular markers commonly used for the diagnosis of liver cancer are $\alpha$-L-fucosidase and PIVKA (protein in vitamin $\mathrm{K}$ absence or Des-gamma-carboxy prothrombin).

\section{Pathological Diagnosis of Liver Cancer}

The Pathological Diagnostic Criteria for Liver Cancer

The pathological diagnosis must be combined with clinical evidence and an overall understanding of the patient's history of HBV/HCV infections, tumor serum markers, and imaging examinations.

Guidelines for the Pathological Diagnosis of Liver Cancer

The guidelines for the pathological diagnosis of liver cancer are composed of standard procedures for sample handling, specimen sampling, pathological examination, and pathology report.

(1) Regarding specimen handling, the surgeon should indicate the site and type of each specimen on the pathology application form. The surgical margin and important lesions can be stained with dyes or labeled with sutures [24, 25]. 


\section{Liver

(2) Regarding specimen sampling, prepared sections from all tumor tissues exhibiting different macroscopic appearances should be collected [26-28]. In addition, the site and number of specimens actually obtained must consider the diameter and number of tumors [24] (evidence level 2).

(3) The main points for the pathology description are the following:

(a) Gross description of specimens. Besides the features of tumor, their relationship with blood vessels and bile ducts, status of capsulation, adjacent liver tissue lesions, type of liver cirrhosis, and distance between tumor and resection margin should be specifically described.

(b) Microscopic description. Follow the World Health Organization (WHO) 2010 edition of "WHO Classification of Tumours of the Digestive System" for the diagnosis of liver cancer. The following information should be described: degree and range of tumor necrosis (e.g., post-TACE), lymphocyte infiltration, and interstitial fibrosis; growth pattern of liver cancer (including microvascular invasion [MVI], satellite nodules, etc.); and evaluation of chronic liver diseases. The simple Scheuer score system and Chinese Criteria for Histological Grading and Staging of Chronic Virus Hepatitis [29,30] should also be used. MVI refers to the presence of cancer cell clusters in the blood vessels lined with endothelial cells, which are most pronounced in the branch of portal vein (including the intracapsular blood vessels) under microscopic observation [31] (evidence level 1). MVI is an important factor for the evaluation of invasiveness and recurrence risk of liver cancer and for the selection of treatment plan; it should be used as a routine parameter for pathological examination [32-34] (evidence level 2).

(c) Immunohistochemical examination. Commonly used hepatocyte markers include Hep Par-1, GPC-3, CD10, Arg-1, and GS. The commonly used bile duct markers include MOC31, HNF1b, and MUC-1. Immunohistochemical markers should be used in proper combination, and the differential diagnosis should be performed between HCC and ICC as well as between primary liver cancer and metastatic liver cancer.

(d) Special types of liver cancer. In mixed-type carcinoma of the liver, both HCC and ICC components are present in the same tumor nodule. In biphenotypic carcinoma of the liver, HCC also expresses cholangiocarcinoma protein markers.

Pathological Diagnosis Report for Liver Cancer

The pathological diagnosis report for liver cancer consists of the gross description of specimens, microscopic description, immunohistochemical examination results, typical pathological photos, and pathological diagnosis name. In addition, molecular pathological examination results related to the clonal origin of liver cancer, drug target testing, biological behavior evaluation, and prognosis judgment can be included for clinical reference.

\section{Clinical Criteria for the Diagnosis of Liver Cancer and Road Map}

HBV or HCV and liver cirrhosis are high-risk factors for liver cancer. These have an important value for the diagnosis of liver cancer and differential diagnosis of hepatic spaceoccupying lesions. In recent years, more attention has been given to the association between nonalcoholic steatohepatitis and liver cancer.

AFP helps to establish a clinical diagnosis of HCC when imaging examination is not fully adequate, especially in the rural or remote area. An AFP level of $\geq 400 \mu \mathrm{g} / \mathrm{L}$ is highly suggestive of liver cancer after the exclusion of pregnancy, chronic or active liver diseases, and embryonic gonadal tumors.

The clinical diagnosis of liver cancer should be established in accordance with the steps shown in the road map and by taking into account the high-risk factors for liver cancer, imaging characteristics, and serological molecular markers (Fig. 1). 


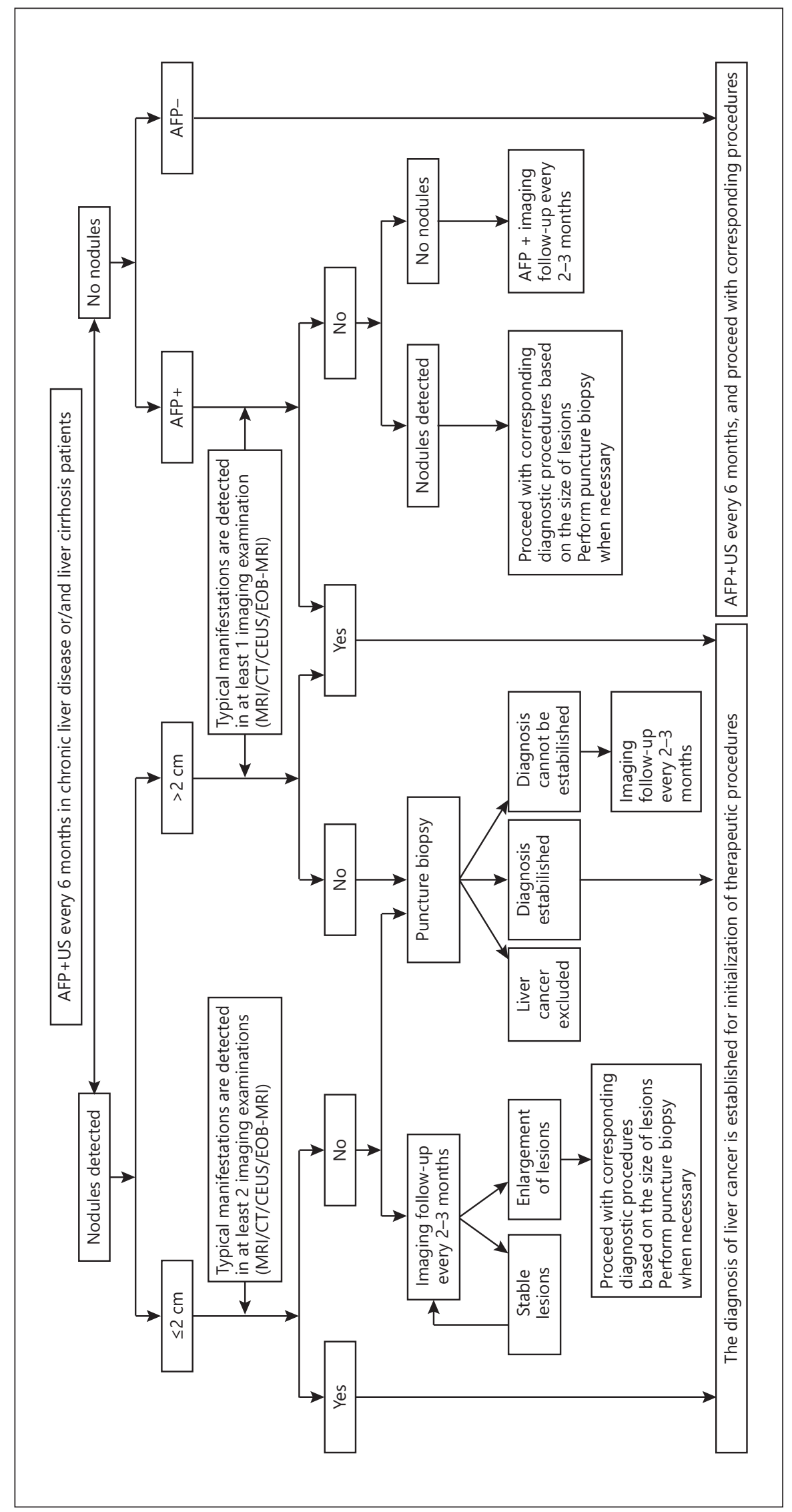

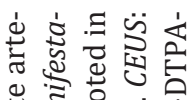

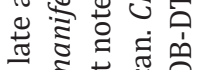

$\lambda$ 륨

兽 छ

约

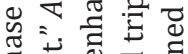

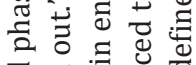

즌 몽

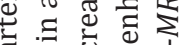

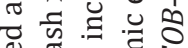

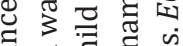

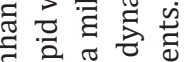

वृ

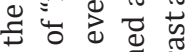

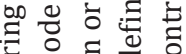

छे ฮี ठे

y 苛芯帘

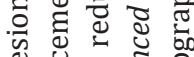

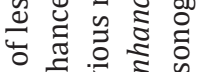

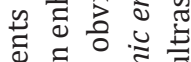

ฮี

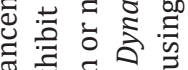

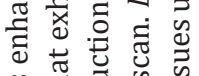

范

品艺

윰

के

㐘 छ च

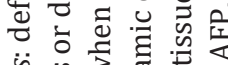

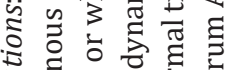

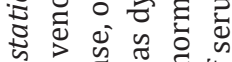

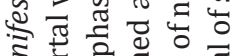

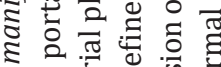

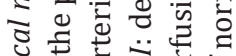

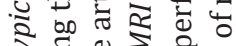

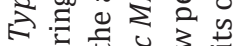

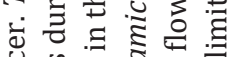

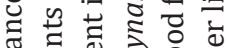

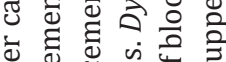

ष्ठ

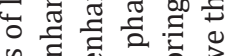

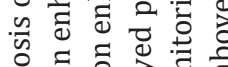

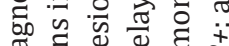

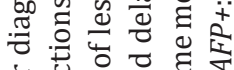

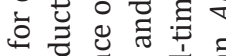

घ

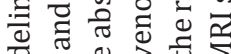

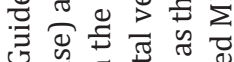

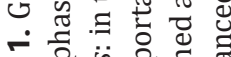

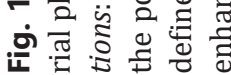


(1) Ultrasonography and AFP testing should be performed a minimum of every 6 months for patients with HBV or HBC or all-cause liver cirrhosis. For intrahepatic nodules with a diameter $\leq 2 \mathrm{~cm}$, the clinical diagnosis of liver cancer can be established when the typical characteristics of liver cancer (i.e., the enhancement mode of "rapid wash in and out") that manifest as obvious enhancement in the arterial phase and reduced enhancement in the portal venous or delayed phase are observed during at least two examinations among the dynamic enhanced MRI, dynamic enhanced CT, ultrasonography, and dynamic gadoxetic acid (Primovist)-enhanced MRI. For intrahepatic nodules with a diameter $>2 \mathrm{~cm}$, the clinical diagnosis of liver cancer can be established when the typical characteristics of liver cancer are noted during any of these four imaging examinations.

(2) For patients with HBV or HCV or liver cirrhosis due to other causes that are found with intrahepatic nodules with a diameter $\leq 2 \mathrm{~cm}$ during follow-up, the diagnosis can be established by liver puncture biopsy or imaging examinations every 2-3 months if the typical characteristics of liver cancer are noted during none or during only one of these four imaging examinations. For patients with intrahepatic nodules with a diameter $>2 \mathrm{~cm}$, the diagnosis can be established by liver puncture biopsy if the characteristics of liver cancer are noted during none of these four imaging examinations.

(3) For patients with HBV or HCV or liver cirrhosis of other causes along with increased AFP, particularly continuously increased AFP, one of these four imaging examinations should be performed to establish the diagnosis. The close monitoring of AFP levels and imaging examination every 2-3 months should be performed after the exclusion of pregnancy, active liver disease, embryonic reproductive tumors, and gastrointestinal cancer if no intrahepatic nodules are identified.

\section{Staging}

Staging of liver cancer is crucial to the prediction of survival and selection of a proper treatment plan. The prognosis of liver cancer is affected by many factors, including tumor factors, the patient's general state of health, and liver function. Therefore, there are a number of staging systems, such as the BCLC, TNM, JSH, and APASL staging systems. The following staging is recommended for liver cancer based on China's medical systems and practice experience: stage Ia, stage Ib, stage IIa, stage IIb, stage IIIa, stage IIIb, and stage IV (Fig. 2).

\section{Treatment}

A feature of liver cancer treatment is the coexistence of multiple methods and multiple disciplines. Therefore, the diagnosis and treatment of liver cancer should be conducted with a multidisciplinary diagnosis and treatment team. The selection of proper treatment approaches should be supported by high-level evidence-based data taking into account the regional and economic differences.

Hepatectomy

Surgical treatment is the most important approach for achieving long-term survival for liver cancer patients. These treatments include hepatectomy and liver transplantation.

Basic Principles for Hepatectomy

Thoroughness. Complete removal of the tumor to ensure that the surgical margin is free of any residual tumor. 


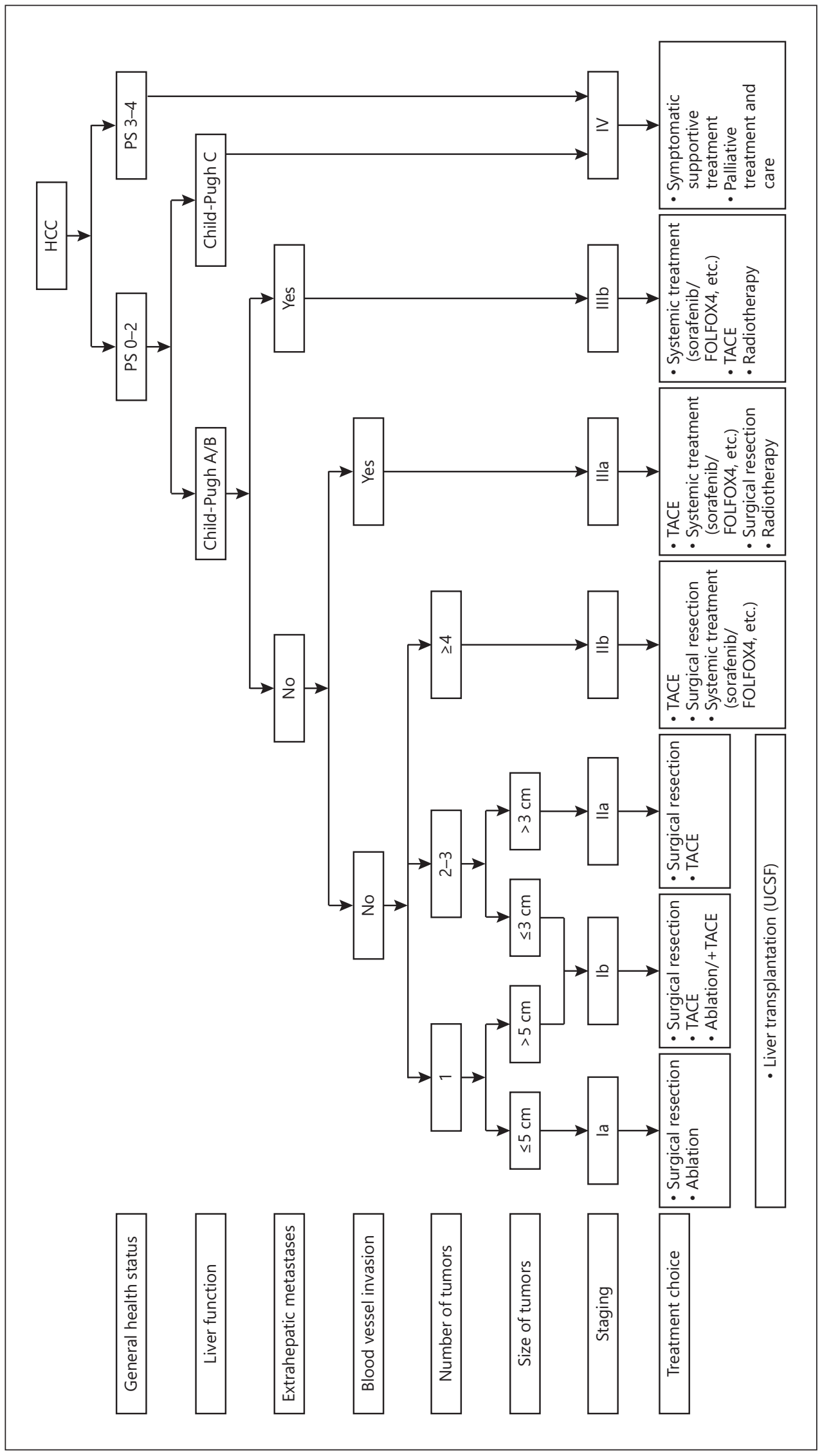

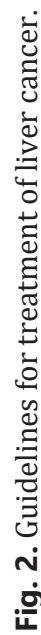




\section{Liver Cancer}

Safety. Preservation of sufficient functional liver tissues (with good blood supply and blood and bile outflow) to compensate liver function and reduce operative mortality and surgical complications following surgery.

Evaluation of Preoperative Liver Function Reserve

Overall evaluation of the patient's general condition and liver function reserve (LFR) should be performed before surgery. Performance status (PS) proposed by the Eastern Cooperative Oncology Group (ECOG) is commonly used to evaluate the patient's general condition. The Child-Pugh score, indocyanine green (ICG) clearance test [35], and transient elastography for liver stiffness measurement [35-38] are used to evaluate LFR. CT and/or MRI are used for measurements of the future remnant liver volume to calculate the percentage of the remaining liver volume in the standardized liver volume if the preservation of a small volume of liver tissues is expected [36]. Child-Pugh grade A and ICG-R15 $<20-30 \%$ are generally considered prerequisites for hepatectomy. A future remnant liver volume accounting for more than $40 \%$ (for patients with liver cirrhosis) or more than $30 \%$ (for patients without liver cirrhosis) of the standardized liver volume is another prerequisite for surgical resection [39].

Indications for Hepatectomy

(1) Liver cancer stages Ia, Ib, and IIa in patients with good LFR are the best indications for surgical resection. Results of recent studies have shown better long-term efficacy after surgical resection [40-42] (evidence level 1), although some other studies demonstrated equivalent efficacy of radiofrequency ablation (RFA) for resection of liver cancer with a diameter $\leq 3 \mathrm{~cm}[43]$ (evidence level 1).

(2) In some stage IIb and IIIa patients, surgical resection may produce a better outcome than other treatment approaches [44, 45] (evidence level 1); however, a more careful preoperative evaluation is required. For patients with multiple liver cancers, relevant studies have demonstrated that those with $\leq 3$ tumors may benefit from surgery when surgical safety criteria are met $[44,46]$ (evidence level 1). For patients with more than 3 tumor nodules, surgical resection, in most cases, is not superior to nonsurgical treatments (e.g., TACE).

(3) For some stage IIb and IIIa patients, surgical resection can be considered if patients have more than 3 tumor nodules that are localized to the same segment or lobe or if RFA can be performed for some lesions during surgery. Surgical removal of the tumor and embolus can be considered if the tumor is localized to one lobe and the tumor emboli are expected to be completely resected during surgery or if the patients have obstructive jaundice because of tumor emboli in the bile duct and the intrahepatic tumors are resectable. For patients with portal lymph node metastases, intraoperative lymph node dissection or postoperative external radiation therapy can be performed in addition to tumor resection, and involvement of the adjacent organs can be resected altogether.

In addition, hepatic artery ligation, which is currently less frequently used and, in some cases, is used for surgical hemostasis of bleeding from rupture of liver cancer, and/or the hepatic artery and portal vein catheterization chemotherapy or other intraoperative local treatments considered for liver cancer that is confirmed as unsuitable for resection during surgical exploration.

Criteria for Curative Resection of Liver Cancer

(1) Criteria based on intraoperative findings are the following: (1) no macroscopic tumor emboli are noted in the hepatic vein, portal vein, bile duct, or inferior vena cava; (2) in the absence of involvement of an adjacent organ, portal lymph node, or distal metastases; and (3) the distance between the surgical margin and tumor boundary is more than $1 \mathrm{~cm}$ or histo- 
logical examination of the surgical margin is tumor-free if the distance between the surgical margin and tumor boundary is less than $1 \mathrm{~cm}$.

(2) Criteria based on postoperative findings are the following: (1) ultrasonography, CT, and MRI (two of these examinations are mandatory) within 2 months after resection confirm the absence of tumor lesions; and (2) quantitative AFP testing should be performed within 2 months after resection to ensure that AFP decreases to the normal range (the time to normalization of AFP is more than 2 months in isolated patients) if the AFP levels were increased preoperatively.

Surgical Resection Techniques

Commonly used surgical techniques include hepatic inflow and outflow control, parenchymal transection, and hemostatic techniques. Experienced physicians can perform laparoscopy or robot-assisted laparoscopic hepatectomy. Minimally invasive procedures have advantages such as less invasiveness and rapid postoperative recovery [47] (evidence level 2); however, prospective, multicenter, randomized, controlled studies to evaluate the longterm efficacy of minimally invasive procedures are warranted. Indications for laparoscopic hepatectomy are: (1) lesions are located in Couinaud segments II, III, IVb, V, and VI; (2) the size of the lesions is generally not more than $10 \mathrm{~cm}$, without affecting the anatomy of the first and second hepatic hilums; and (3) surgeons have rich experience and can perform laparoscopic hemihepatectomy, trihepatectomy, and hepatectomy of Couinaud segments I, VII, and VIII step by step.

Insufficient future remnant liver volume due to a major resection or concerns regarding the function of the remnant liver are the main reasons that hinder the application of radical resection. The following methods can be used for improving resectability:

(1) Surgical resection can be performed after induction of tumor shrinkage by preoperative TACE in some patients $[48,49]$.

(2) Portal vein embolization (PVE) or portal vein ligation (PVL) can be applied to increase the future remnant liver volume [50]. The postoperative morbidity and mortality of portal vein embolization are $19-56 \%$, and $0-11.5 \%$, respectively [51]. Concurrent use of TACE can reduce the risk of tumor progression during the waiting time because 4-6 weeks are needed for the volume of the remnant liver to increase [52].

(3) Associating the liver partition and portal vein ligation for staged hepatectomy (ALPPS) is a new technique that has been developed in recent years and is used for patients in whom the estimated remnant liver volume is less than $30-40 \%$ of the standardized liver volume. After liver transection and ligation of the portal vein branch of the affected side, 1-2 weeks are generally needed for the future remnant liver of the unaffected side to grow by $30-70 \%$. Then, resection is performed when the future remnant liver volume is more than $30-40 \%$ of the standardized liver volume. Preoperative evaluation should include liver cirrhosis, the patient's age and ability to tolerate two surgeries within a short period of time, and the risk of rapid tumor progression [53]. Laparoscopy or ablation can be used to minimize the trauma associated with the procedure [54]. Contraindications for ALPPS include the following: (1) the presence of unresectable extrahepatic metastases; (2) serious portal hypertension; (3) poor general condition; and (4) tumor nodules macroscopically noted in the future remnant liver after the first surgery. ALPPS is associated with an increased incidence of complications and mortality, although it can improve the resection rate of liver cancer within a short period of time. Therefore, extra care should be taken when selecting the right candidates for this procedure.

(4) For tumors that are found with serious liver cirrhosis and multiple nodules and that have deep positions during surgical exploration, intraoperative RFA can minimize surgical risks. 
Both anatomic and nonanatomic resections are commonly used techniques. For large tumors, the survival benefit of anterior approach without dissecting the perihepatic ligaments before transection is still controversial [55]. For multiple tumors, surgical resection in combination with intraoperative ablation (e.g., intraoperative RFA) can be performed to allow for resection of the tumors along the liver edges and simultaneous ablation of deep tumors. For patients with tumor emboli in the portal vein, the portal venous flow of the unaffected side should be temporarily interrupted during portal vein embolectomy not only for avoiding dissemination of tumor emboli [56] but also for avoiding bleeding. For patients with tumor emboli in the hepatic vein or vena cava, total vascular occlusion can be performed to ensure the removal of the whole tumor emboli $[57,58]$.

Preoperative Treatment

For unresectable tumors, hepatic artery ligation and catheterization, TACE, and external radiation therapy may result in tumor downstaging and consequently provide some patients with opportunities for radical resection. Better long-term survival may be achieved by patients undergoing resection after downstaging [48]. For resectable liver cancer, preoperative TACE is not associated with improved survival $[59,60]$ (evidence level 2).

Postoperative Treatment (for Prevention and Treatment of Metastasis and

Recurrence)

The 5-year recurrence and metastasis rate after surgical resection is up to $40-70 \%$, which may be related to the preexisting minimal disseminated lesions or multicentric origin. Therefore, close follow-up must be performed for all patients. In the case of tumor recurrences, repeat resection, local ablation, TACE, radiation therapy, or systemic treatment [61] can be used based on the characteristics of tumor recurrences. For patients at high risk for tumor recurrence, postoperative TACE has been shown to be somewhat effective because it helps detect and control residual minimal intrahepatic cancer [62] (evidence level 4). However, further investigations are warranted for such a conclusion. In addition, the concurrent use of chemotherapy via portal vein catheterization and TACE after resection can prolong survival for patients with tumor emboli in the portal vein [63]. The use of interferon- $\alpha$ to reduce recurrence risk and prolong survival remains controversial [64], although this effect has been demonstrated in some clinical studies [65-67] (evidence level 1). There are reports of the association between miR-26a expression in liver cancer and adjuvant therapy with interferon- $\alpha$ [68]. Further multicenter, randomized, controlled studies are needed for such results. Huai'er granules (traditional Chinese medicine) have been shown by large-scale, domestic, multicenter, randomized, controlled studies to be effective for the prevention of recurrence and metastasis in patients undergoing radical resection for liver cancer.

\section{Liver Transplantation}

Indications for Liver Transplantation for Liver Cancer

Liver transplantation, which is a radical treatment approach for liver cancer, is indicated for patients with decompensated cirrhosis and small liver carcinoma. The appropriate indications are crucial for improving the efficacy of liver transplantation and ensuring the fair and proper use of precious donator liver resources.

The Milan criteria and University of California San Francisco (UCSF) criteria are commonly used indications for liver cancer in patients in international communities; however, no uniform criteria have been established in China. A number of criteria have been proposed, including Shanghai Fudan criteria [69], Hangzhou criteria [70], West China criteria [71], and Sanya consensus. All of these criteria agree regarding the absence of large vessel involvement, lymph node metastases, and extrahepatic metastases, but they diverge regarding the size and 


\section{Liver

number of tumors. These domestic criteria extend indications of liver transplantation for liver cancer to varying degrees to allow more patients to benefit from liver transplantation without significantly reducing postoperative overall survival and tumor-free survival as compared with the Milan criteria. However, multicenter collaborative studies are still warranted for support and confirmation of such a practice and for obtaining high-level evidence from evidence-based medicine. Therefore, the UCSF criteria are recommended by these guidelines after a full discussion by the expert group.

Prevention of Posttransplant Recurrence of Liver Cancer

Tumor recurrence significantly reduces posttransplant survival. Its risk factors include tumor stage, AFP level, and cumulative dose of immunodepressants. Reduced exposure to calcineurin inhibitors early after liver transplantation may be associated with lower tumor recurrence rates [72] (evidence level 2). The use of mTOR inhibitor immunosuppressive therapy after liver transplantation for liver cancer can also prevent tumor recurrence and improve survival [73, 74] (evidence level 2); however, multicenter, randomized, clinical studies are still warranted for further investigation.

\section{Local Ablation Therapy}

Only approximately $20-30 \%$ of liver cancer patients have the opportunity to undergo surgical resection because a large portion of liver cancer patients have liver cirrhosis or are already at the middle/terminal stage at the time of diagnosis. However, surgery is the best treatment choice to obtain long-term survival. Local ablation therapy, which has been widely used in recent years, provides early liver cancer patients with a curative outcome.

Local ablation therapy is designed to directly destroy tumor tissues using physical or chemical methods under the guidance of imaging techniques. These techniques mainly include RFA, microwave ablation (MWA), cryotherapy, high-power focused ultrasonography ablation, and percutaneous ethanol injection (PEI). Local ablation therapy is most often performed under the guidance of ultrasonography, which has the advantages of real time and high efficiency. CT and MRI in combination with multimode imaging systems can be used to monitor lesions when ultrasonography is unable to do so. CT and MRI guidance techniques can also be used for the ablation of metastases in the lungs, adrenal glands, and bones.

Ablation is performed by percutaneous, laparoscopic, or laparotomy approaches. Most small liver cancer can be percutaneously ablated, which has the advantages of cost-effectiveness, ease of use, and minimal invasion. For subcapsular tumors, particularly tumors protruding beyond the liver capsule, which are associated with high risks for percutaneous puncture ablation, or for liver cancers for which imaging guidance is difficult, ablation via laparoscopic or laparotomy approaches can be considered.

Solitary tumors with a diameter $\leq 5 \mathrm{~cm}$ or no more than 3 tumor nodules in a large tumor $\leq 3 \mathrm{~cm}$ without vascular invasion and distal metastasis are the best candidates for local ablation therapy; an outcome comparable to that of radical resection can be achieved for patients with Child-Pugh class A or B [75-77] (evidence level 1). However, local ablation is also used in combination with TACE for patients with inoperative solitary or multiple tumors with a diameter of 3-7 cm [78, 79] (evidence level 1).

Common Ablation Therapies

Radiofrequency Ablation. RFA is the most commonly used minimally invasive therapy for liver cancer and has the advantages of ease of use, less invasiveness, good efficacy, and relatively low cost. The tumor-free survival rate of RFA is slightly lower than that of surgical resection for patients with tumors $\leq 3 \mathrm{~cm}[41,75]$ (evidence level 1). RFA has significant advantages such as fewer treatment sessions and higher long-term survival rates as 


\section{Liver

Zhou et al.: 2017 Liver Cancer Guidelines in China

compared with PEI. RFA ablates the tumor as a whole while minimizing the damage to nontumor tissues on the premise that the range of tumor infiltration and satellite lesions is covered. Therefore, highly accurate imaging examinations are important prior to treatment. Enhanced ultrasonography helps confirm the actual size and shape of the tumor, defines the boundary of tumor infiltration, and detects minimal liver cancers and satellite lesions, thus providing a reliable reference for the determination of an ablation regimen for the inactivation of tumors.

Microwave Ablation. MWA is a type of thermal ablation commonly used in China. No significant differences in local efficacy, incidence of complications, or long-term survival have been observed between MWA and RFA. Its characteristics are its high ablation efficiency, which avoids the "heat sink effect" associated with RFA. For tumors with an abundant blood supply, the major feeding artery of the tumor can be interrupted by coagulation for improved efficacy. The establishment of a temperature monitoring system helps regulate the range of an effective ablating area and ensures coagulation. Randomized, controlled studies have shown no statistically significant differences in local efficacy, complications, or survival between these two techniques [80] (evidence level 1). The selection of MWA or RFA should be based on the size and position of the tumor to choose a more appropriate ablation method [81] (evidence level 3).

Percutaneous Ethanol Injection. PEI is indicated for liver cancers with a diameter $\leq 3 \mathrm{~cm}$. PEI has good ablative effects and similar long-term efficacy for liver cancers with a diameter $\leq 2 \mathrm{~cm}$, despite its higher local recurrence rate than RFA. The advantage of PEI is its safety, and it is particularly suitable for cancers near the hepatic hilar region, gallbladder, and gastrointestinal tissues, whereas thermal ablation (RFA and MWA) may lead to damage under these circumstances.

Technical Requirements for Local Ablation Procedure

(1) The operator must receive adequate training and have sufficient experience. A thorough and detailed evaluation of the patient's general health status, liver function, and the size, position, and number of tumors should be performed prior to treatment. Attention should be given to the relationship between the tumor and adjacent organs. A proper puncture tract and ablation area should be determined to secure a sufficient safety range.

(2) Appropriate imaging techniques (ultrasonography or CT) and ablation methods (RFA, MWA, or PEI) should be selected based on the size and position of the tumor.

(3) The tumor should be at least $5 \mathrm{~mm}$ away from the bile ducts in the hepatic hilar region. Ablation therapy is not recommended for lesions $>5 \mathrm{~cm}$. For multiple lesions or larger tumors, TACE followed by ablation therapy can be considered based on the liver function, which produces a better outcome than ablation therapy alone.

(4) The range of ablation should cover a 5-mm distance beyond the tumor boundary. For ill-defined irregular infiltrating tumors or metastases, the range of ablation is recommended to be extended as appropriate if adjacent liver tissues and structural conditions permit.

Surgical Resection or RFA for Patients with Tumors $\leq 5 \mathrm{~cm}$

Several randomized, controlled trials and systematic retrospective analyses have used surgical resection as the first choice of therapy [40-42, 75] (evidence level 1). In clinical practice, the appropriate initial treatment approach should be selected after thorough consideration based on the patient's general health status and liver function, the size, number, and position of tumors, as well as the skill of the physician who performs ablation therapy. Surgical resection is generally believed to be the first choice if the patients can tolerate hepatectomy and if liver cancers are located at shallow sites or the margin of the liver. Local ablation therapy can be used as another choice in addition to surgical resection. For 2-3 tumors 
located in different areas, or for tumors that are deep in the liver, local ablation therapy has efficacy equivalent to that of surgical resection and results in radical ablation using minimally invasive techniques.

Evaluation after Ablation Therapy

Dynamic enhanced CT or MRI or ultrasonography is usually used to assess the response to ablation approximately 1 month after ablation therapy. The response to ablation can be divided as follows: (1) complete response, whereby dynamic enhanced CT or MRI shows no enhancement in the area in which the tumor is located in the arterial phase; and (2) incomplete response, whereby dynamic enhanced CT or MRI shows enhancement of the tumor in the arterial phase, which is suggestive of residual tumors. Repeat ablation therapy can be performed for patients with a residual tumor after initial ablation. Ablation therapy should be considered a failure, and treatment should be switched if the presence of a residual tumor is confirmed after two sessions of ablation therapy. Follow-up should be performed after complete response is achieved. Tumor markers, ultrasonography, MRI, or CT should be performed every 2-3 months for early detection of local recurrent lesions and new intrahepatic lesions, and effective control of tumor progression should be performed using percutaneous ablation therapy.

\section{Transarterial Chemoembolization}

TACE is an interventional treatment used in China. It has been recognized as one of the most common nonsurgical treatments for liver cancer [80, 82-86] (evidence level 1).

Basic Principles

(1) TACE should be performed using DSA; (2) Clinical indications must be strictly followed; (3) Superselective catheterization of tumor feeding arteries must be ensured; (4) The patient's liver function must be properly protected by avoiding occlusion of the feeding vessels to the nontumor liver; (5) Standardized and individualized chemotherapy protocols must be performed; (6) If the tumor continues to progress after 4-5 courses of TACE, other treatments should be considered or concurrently used (e.g., surgery, local ablation, systemic treatment, radiation therapy, etc.).

\section{Indications}

TACE is indicated for: (1) a portion of stage IIb, IIIa, and IIIb patients with Child-Pugh class A or B liver function and an ECOG score of 0-2; (2) stage Ib and IIa patients with resectable lesions who cannot or will not undergo surgery for other reasons (e.g., older age, severe cirrhosis) and instead undergo interventional treatment as the first-line nonsurgical option; (3) multiple nodular tumors; (4) a main portal vein that is not completely blocked or is completely blocked but the compensatory collateral blood vessels have formed between the hepatic artery and portal vein; (5) portal hypertension bleeding as a result of rupture of the liver tumor and hepatic artery-portal venous static shunt; (6) management of local pain and bleeding and blocking of the arteriovenous fistula; and (7) tumor recurrence after liver resection as a preventive measure, because DSA is capable of early detection of residual cancer or recurrent lesions.

Contraindications

(1) Severe liver dysfunction (Child-Pugh class C), including jaundice, hepatic encephalopathy, refractory ascites, or hepatorenal syndrome; (2) severe coagulation dysfunction that cannot be corrected; (3) completely embolized main portal vein with few collateral blood vessels formed; (4) active HBV infection or active infections that complicate the condition and 


\section{Liver

cannot be treated simultaneously; (5) wide distant metastasis with an estimated survival of $<3$ months; (6) cachexia or multiple organ failure; (7) liver tumors accounting for $\geq 70 \%$ of the entire liver (staged embolization with small amounts of iodized oil emulsion can be considered if liver function is normal); (8) significant reductions in peripheral blood leukocytes and platelets, white blood cell (WBC) count $<3.0 \times 10^{9} / \mathrm{L}$ (when due to hypersplenism but not toxicity of chemotherapy; therefore, it is not an absolute contraindication for TACE), and platelets $<50 \times 10^{9} / \mathrm{L}$; and (9) renal dysfunction (creatinine $>2 \mathrm{mg} / \mathrm{dL}$ or creatinine clearance rate $<30 \mathrm{~mL} / \mathrm{min}$ ).

Main Points of the Operating Procedures [87] (Evidence Level 3)

(1) Hepatic arteriography. The Seldinger method is often used for hepatic arteriography, whereby the catheter is placed in the celiac artery or common hepatic artery following percutaneous femoral artery catheterization. Image acquisition should include the arterial phase, parenchymal phase, and venous phase. Images of the superior mesenteric artery should be obtained with caution to look for the collateral blood supply. Angiography should be carefully analyzed to determine the site, size, and number of feeding arteries of the tumor.

(2) Specific surgeries may include the following depending on the procedural options: (a) hepatic arterial infusion chemotherapy, whereby infusion chemotherapy is delivered through superselective catheterization in the feeding arteries (commonly used drugs are anthracyclines and platinum); (b) hepatic artery embolization, whereby the feeding arteries of tumors are blocked with embolization agents; (c) hepatic arterial chemoembolization, whereby the mixture of chemotherapy drugs and embolization agents is infused through the tumorfeeding artery.

The most commonly used embolization agents for TACE are lipiodol emulsion, standardized gelatin sponge particles, and drug-eluting beads (DEBs). First, a portion of chemotherapy drugs is generally infused over a period of not less than $20 \mathrm{~min}$, followed by embolization with the emulsion mixture of the other portion of chemotherapy drugs and lipiodol. The dose of lipiodol is usually $5-20 \mathrm{~mL}$, but it is not more than $30 \mathrm{~mL}$. The boundary is defined as the formation of dense lipiodol deposition in the tumor area and the presence of small portal vein branch shadows around the tumor under the fluoroscopic monitoring. Granular embolization agents (e.g., standardized gelatin sponge particles, microspheres, polyvinyl alcohol particles) should be used after embolization with lipiodol emulsion. The use of a well-mixed emulsion of lipiodol and chemotherapy drugs is necessary to avoid embolization of normal liver tissues as a result of agent reflux or the entry of the agents into nontarget organs. All tumor-feeding arteries should be embolized to achieve devascularization of the tumor.

\section{Common Adverse Reactions to TACE}

Postembolization syndrome is the most common adverse effect of TACE. The major symptoms are fever, pain, nausea, and vomiting. Fever and pain are the results of local tissue ischemia and necrosis when the hepatic artery is embolized, and nausea and vomiting are associated with chemotherapy drugs. In addition, puncture site bleeding, decreased WBCs, transient abnormal liver function, renal dysfunction, and voiding difficulties are commonly observed. In general, these adverse effects will last 5-7 days after the procedure and will disappear for most patients after symptomatic treatment.

Response Evaluation

Tumor response should be evaluated in accordance with mRECIST and EASL criteria. The long-term efficacy parameter is overall survival and the short-term efficacy parameters are imaging response of the tumor and time to progression. 


\section{Liver

Main Factors That Affect the Long-Term Efficacy of TACE [82]

The main factors are: (1) degree of liver cirrhosis and liver function status; (2) serum AFP level; (3) volume and burden of the tumor; (4) extent of integrity of the tumor capsule; (5) portal vein tumorous thrombus; (6) blood supply of the tumor; and (7) pathological types of tumor.

Follow-Up and Treatment between TACE Sessions

CT and/or MRI, tumor marker tests, liver and renal function tests, and blood count tests are usually recommended 4-6 weeks after the first session of TACE. More TACE sessions can be postponed if imaging shows thick lipiodol deposition in the liver tumor, necrosis of the tumor tissues, and the absence of tumor enlargement and new lesions. The frequency of subsequent TACE should be determined based on the response to previous treatment, liver function, and changes in PS. Follow-up can be performed at an interval of 1-3 months or longer. The viability of the tumor should be evaluated using dynamic enhanced CT and/or MRI to determine the need for more TACE. TACE in combination with other treatments is advocated for tumor control, improved quality of life, and long-term survival.

More Considerations for TACE

(1) Microcatheter superselective catheterization is advocated. Catheterization of the tumor-feeding arteries and accurate infusion of lipiodol emulsion and granular embolization agents should be ensured for improved efficacy and protection of liver function.

(2) The tumor emboli in the portal vein trunk can be effectively treated to resume blood flow by portal vein stenting and I-125 seed strip or I-125 seed portal vein stenting [88] (evidence level 2).

(3) TACE can be used in combination with ablation therapy. There are two approaches: (1) sequential ablation, whereby TACE is followed by radiofrequency or MWA at an interval of 1-4 weeks; and (2) concurrent ablation, whereby radiofrequency or MWA is performed during TACE, resulting in significantly improved clinical efficacy and reduced hepatic impairment [86] (evidence level 2).

(4) Granular embolization agents include standardized gelatin sponge particles, polyvinyl alcohol particles, microspheres, and DEBs. Standardized gelatin sponge particles in combination with lipiodol are commonly used for conventional TACE. DEBs are a new type of embolization agent carrying chemotherapy drugs. A previous study has reported the advantages of DEBs in objective response rates and disease control rates [89]. However, a recent study has reported that no significant differences in local tumor response and patient survival have been noted for DEB-TACE and conventional TACE [90-92].

(5) TACE can be combined with another local treatment or systemic treatment [82], for example: (1) TACE in combination with ablation therapy (RFA, MWA, etc.) [88] (evidence level 2); (2) TACE in combination with radiation therapy [84] (evidence level 2), which could be selectively used for patients with tumor emboli in the portal trunk and inferior vena cava or localized large HCC after TACE; (3) TACE in combination with surgical resection, which should be recommended for large HCCs that have shrunk after TACE and are suitable for surgical resection [88] (evidence level 3); and (4) TACE in combination with systemic treatment, including molecular target drugs, arsenic trioxide, radiolabeled drugs, gene therapy, immunotherapy, and systemic chemotherapy [93, 94].

\section{Radiation Therapy}

Radiation therapy (called radiotherapy) includes external beam radiotherapy and internal radiotherapy. External beam radiation is delivered from outside the body by aiming 


\section{Liver Cancer}

rays (photons or particle radiation) from the radiotherapy machine to the tumor. Internal radiotherapy is delivered by the implantation of radionuclides into the tumor through body tracts or needle tracts.

External Beam Radiotherapy

Indications. For stage IIIa and IIIb patients with tumor emboli in the portal vein/inferior vena cava or extrahepatic metastases, palliative radiotherapy is suggested. Some patients may have the opportunity of surgical resection after tumor shrinkage or downstaging [9597] (evidence level 3). External beam radiotherapy can also be used as bridging treatment when waiting for liver transplantation or in combination with treatment [98]. For patients with extrahepatic metastases, external beam radiotherapy can be used for relieving symptoms such as pain, obstruction, or bleeding and for controlling tumor progression, thereby prolonging survival [99-101] (evidence level 3). For centrally located tumors with narrow surgical margins $\leq 1 \mathrm{~cm}$, adjuvant radiotherapy can be used postoperatively [102] (evidence level 3).

Irradiated Volume. Gross tumor volume (GTV) can be defined on enhanced CT; however, MRI should also be used when necessary. Lymph node metastases are rare in liver cancer; therefore, the lymph drainage area is not included in the clinical target volume (CTV). For patients with lymph node metastases, the lymph drainage area of the next station must be included in CTV. In other circumstances (e.g., confined to intrahepatic area, tumor emboli, adrenal metastases, pulmonary metastases), a 2- to 4-mm margin needs to be added around the GTV [103]. The magnitude of respiratory liver tumor motion can be evaluated using X-ray fluoroscopy; however, the four-dimensional (4D) CT simulation technique is more accurate. The planning target volume is generally extended by $5-15 \mathrm{~mm}$ on the basis of CTV. The intrahepatic target volume must be delineated on the basis of images during the arterial and venous phases. MRI provides good visibility of intrahepatic lesions, and PET/CT presents extrahepatic lesions well. The determination of the target volume should be based on as many multiple imaging examinations as possible. An important principle for the irradiation design for liver cancer is to fully utilize the remarkable regeneration capability of normal liver tissues. Regarding the irradiation design, particularly for large tumors, it is necessary to spare enough irradiation-free volume to allow some normal liver tissues to regenerate.

Irradiation Dose. The safe dose for stereotactic radiotherapy is $<45 \mathrm{~Gy} / 3$ fractions for a normal liver volume $>700 \mathrm{~mL}$ and $<54 \mathrm{~Gy} / 3$ fractions for a normal liver volume $>800 \mathrm{~mL}$ for Child-Pugh A patients. The usual recommended irradiation dose is $\geq 30-60 \mathrm{~Gy} / 3-6$ fractions. For patients scheduled for palliative radiotherapy, the irradiation dose for tumors depends on the tolerance dose of the whole liver and/or adjacent gastrointestinal tract. Most reports have shown a conventional fractionated dose of 40-70 Gy. The tolerance dose for the whole liver is 28-30 Gy [104] for conventional fractionated radiotherapy and 23 Gy [105] for nonconventional hypofractionated radiotherapy (a fractionated dose of 4-8 Gy) for patients with Child-Pugh class A liver function. The tolerance of the liver to radiation is significantly reduced in Child-Pugh class B patients. The tolerance dose of the gastrointestinal tract is lower than the RTOG-recommended dose for Asian HCC patients as a result of gastrointestinal bleeding and poor blood clotting due to coexisting liver cirrhosis and hypersplenism [106].

Radiotherapy Techniques. The use of 3D conformal radiotherapy (CRT), intensity-modulated radiation therapy (IMRT), image-guided radiation therapy, or stereotactic body radiation therapy is recommended. Image-guided IMRT is superior to 3D CRT [107]. The tomotherapy system is the radiation system designed for image-guided IMRT; it is suitable for patients with multiple lesions. The following criteria for stereotactic radiotherapy for liver cancer must be met: a 4D CT scanner or tumor tracking system; extreme precision in patient 


\section{Liver

Zhou et al.: 2017 Liver Cancer Guidelines in China

positioning and immobilization; personalized image correction prior to initialization of radiotherapy; the capability of the radiation device to focus beams on the tumor; and sharp dose gradients to spare normal tissues. There is a lack of high-level clinical data supporting the superior survival of proton radiotherapy compared to photon radiotherapy for liver cancer patients. Respiratory motion is the main cause of liver tumor motion and deformation during radiotherapy. Multiple techniques can be used to reduce the impact of respiratory motion, including the gating technique, real-time tracking, breathing control technique, and internal target volume determination based on 4D CT. Abdominal compression is easy to apply and reduces respiratory liver motion. The abdominal compression at the upper segment of the line between the xiphoid process and umbilicus can minimize respiratory liver motion [108].

Internal Radiotherapy

Radioactive particle implantation is an effective local method for the treatment of liver cancer; this treatment includes Y-90 microsphere treatment $[109,110]$, iodine-131 monoclonal antibody [111], radioactive lipiodol [112], and iodine-125 seed implantation. Radioactive particles that continuously emit low-energy X-rays, $\gamma$-rays, or $\beta$-rays can maximize the destruction of tumor cells by continuous low-dose radiation after being implanted into tumor tissues or tumor-invaded body canals (portal vein, inferior vena cava, or biliary tract).

\section{Systemic Treatment}

For patients with advanced liver cancer, systemic treatment may reduce tumor burden, relieve tumor-related symptoms, improve quality of life, and prolong survival.

Antitumor Treatments and Their Efficacy

Molecular Target Drugs. Sorafenib is the only molecular target drug approved at this time for the treatment of advanced liver cancer [113]. It is supported by two large-scale international multicenter phase III clinical trials demonstrating survival benefits for patients from different countries and regions and with different liver disease backgrounds [114] (evidence level 1). Liver function should be monitored during treatment with sorafenib. The most common adverse reactions are diarrhea, weight loss, hand-foot syndrome, rash, myocardial ischemia, and hypertension (evidence level 1). These generally occur within 2-6 weeks after initialization of treatment. Sorafenib can be used for patients with Child-Pugh class A (evidence level 1) and class B (evidence level 3) liver function. Sorafenib provides more significant survival benefits for patients with Child-Pugh class A liver function compared with those with Child-Pugh class B liver function [115].

Systemic Chemotherapy. Conventional cytotoxic drugs, including adriamycin, epirubicin, fluorouracil, cisplatin, and mitomycin, have low efficacy, significant side effects, and poor repeatability when they are used as alone or in combination for the treatment of liver cancer. Chemotherapy drugs not only activate HBV replication but also damage liver function, thus leading to a lack of survival benefits from chemotherapy. The EACH study showed that the FOLFOX4 regimen containing oxaliplatin is superior regarding the overall response rate, disease control rate, progression-free survival, and overall survival compared to the conventional chemotherapeutic drug adriamycin and has good tolerability and safety profiles [116] (evidence level 2). Therefore, oxaliplatin has been approved in China for the treatment of local advanced and metastatic liver cancers when surgery and local treatment are unsuitable. Indications for chemotherapy are mainly the following: (1) advanced stage with extrahepatic metastases and tumor emboli in the main portal vein or inferior vena cava; and (2) local advanced stage not amenable to surgery or local therapy. Contraindications of chemotherapy include the following: (1) ECOG PS score $>2$ and Child-Pugh score $>7$; (2) liver function with Child-Pugh class C; (3) WBC count $<3.0 \times 10^{9} / \mathrm{L}$ or neutrophil count $<1.5 \times 10^{9} / \mathrm{L}$, blood 


\section{Liver

platelet count $<60 \times 10^{9} / \mathrm{L}$, and hemoglobin $<90 \mathrm{~g} / \mathrm{L}$; and (4) obvious liver and renal function abnormalities with aminotransferases (AST or ALT) $>5$-fold the upper limit of normal and/ or significantly increased bilirubin $>2$-fold the upper limit of normal, serum albumin $<28 \mathrm{~g} / \mathrm{L}$, and creatinine clearance rate $<50 \mathrm{~mL} / \mathrm{min}$ with active infection. Arsenic trioxide has been recommended for patients with intermediate- or advanced-stage tumors [117] (evidence level 3). However, monitoring of hepatotoxicity and nephrotoxicity is necessary.

Immunotherapy. Immunotherapy for liver cancer mainly includes immune modulators (interferon- $\alpha$, thymopeptide- $\alpha_{1}$ [thymalfasin], etc.) [66], checkpoint inhibitors (CTLA-4 antibody, PD-1/PD-L1 antibody) [118], tumor vaccines (dendritic cell vaccines, etc.), adoptive immunotherapy (cytokine-induced kill cells) $[117,119]$. These treatment approaches have been used for HCC patients. However, large-scale clinical studies are still warranted for further validation.

Traditional Chinese Medicine. Traditional Chinese medicine may improve the quality of life and antitumor immunity and reduce adverse effects from radiotherapy and chemotherapy. There are several modern Chinese herb preparations that have been used for the treatment of liver cancer, including Huai'er granules, Kanglaite injection, Cinobufacini, elemene, and Ganfule (evidence level 4). However, there is a lack of high-level evidence to sufficiently support the benefits of these drugs.

Efficacy Evaluation for Systemic Treatment. For patients using systemic treatment, imaging evaluation is generally performed every 6-8 weeks during treatment in accordance with RECIST 1.1 criteria, taking into account the changes in serum tumor marker (AFP) and degree of tumor necrosis. The overall evaluation should be performed by dynamic monitoring of the patient's PS and treatment-related adverse reactions. The response evaluation criteria based on tumor vascularization and density changes (mRECIST criteria) are recommended for evaluation of the response of patients treated with sorafenib or TACE $[120,121]$. The immune-related response criteria can be used for evaluation of the immunotherapy response [122].

Antiviral Treatment and Other Treatments

For patients with HBV infection, the HBV DNA level should be monitored. Antiviral treatment with nucleoside analogues is essential. Select potent drugs with a low rate of resistance (e.g., entecavir, telbivudine, or tenofovir disoproxil) are recommended. The use of antiviral drugs should be started prior to TACE or chemotherapy because these treatments may lead to active replication of HBV. Antiviral treatment is also associated with lower postoperative recurrence $[123,124]$ (evidence level 1). Therefore, antiviral treatment should be performed throughout treatment for liver cancer.

Liver function may be deteriorated during the natural course of disease or treatment. Therefore, timely and appropriate treatment with liver-protecting drugs (e.g., magnesium isoglycyrrhizinate injection, diammonium glycyrrhizinate enteric-coated capsules, compound glycyrrhizin, reduced glutathione, polyene phosphatidylcholine injection), anti-inflammatory drugs (e.g., broad-spectrum hydrolase inhibitor ulinastatin), and cholagogues and choleretics (e.g., ademetionine, ursodeoxycholic acid) is needed. These drugs may protect liver function, improve treatment safety, lower rates of complications, and improve quality of life.

Supportive Treatment

Adequate rehabilitation exercises can increase immunity. In addition, supportive treatments should be administered, including active analgesic treatment, correction of anemia and hypoalbuminemia, enhanced nutritional support, blood sugar control for patients with diabetes, and treatment of concomitant symptoms such as ascites, jaundice, hepatic encephalopathy, and gastrointestinal bleeding in patients with advanced liver cancer. 
Zhou et al.: 2017 Liver Cancer Guidelines in China

Doctors should understand the mental status of their patients and their families, take active measures to adjust their mental state by reversing the negative mental state to the active mental state, and reduce depression and anxiety by providing them with a sense of safety and comfort through palliative treatment and care.

\section{Acknowledgments}

The authors thank Prof. Meng-Chao Wu, Prof. Zhao-You Tang, Prof. Wan-Yee Lau, Prof. Xiao-Ping Chen, Prof. Xue-Hao Wang, Prof. Yan Sun, and Prof. Shu-Sen Zheng for their contribution to the Guidelines.

\section{Disclosure Statement}

The authors declare no conflicts of interest.

\section{References}

1 Torre LA, Bray F, Siegel RL, Ferlay J, Lortet-Tieulent J, Jemal A: Global cancer statistics, 2012. CA Cancer J Clin 2015;65:87-108.

2 Chen W, Zheng R, Baade PD, Zhang S, Zeng H, Bray F, Jemal A, Yu XQ, He J: Cancer statistics in China, 2015. CA Cancer J Clin 2016;66:115-132.

-3 Zhang BH, Yang BH, Tang ZY: Randomized controlled trial of screening for hepatocellular carcinoma. J Cancer Res Clin Oncol 2004;130:417-422.

4 Salvatore V, Gianstefani A, Negrini G, Allegretti G, Galassi M, Piscaglia F: Imaging diagnosis of hepatocellular carcinoma: recent advances of contrast-enhanced ultrasonography with SonoVue ${ }^{\circledR}$. Liver Cancer 2016;5: $55-66$.

-5 Zeng MS, Ye HY, Guo L, Peng WJ, Lu JP, Teng GJ, Huan Y, Li P, Xu JR, Liang CH, Breuer J: Gd-EOB-DTPA-enhanced magnetic resonance imaging for focal liver lesions in Chinese patients: a multicenter, open-label, phase III study. Hepatobiliary Pancreat Dis Int 2013;12:607-616.

-6 Lee YJ, Lee JM, Lee JS, Lee HY, Park BH, Kim YH, Han JK, Choi BI: Hepatocellular carcinoma: diagnostic performance of multidetector CT and MR imaging-a systematic review and meta-analysis. Radiology 2015;275: 97-109.

7 Ichikawa T, Saito K, Yoshioka N, Tanimoto A, Gokan T, Takehara Y, Kamura T, Gabata T, Murakami T, Ito K, Hirohashi S, Nishie A, Saito Y, Onaya H, Kuwatsuru R, Morimoto A, Ueda K, Kurauchi M, Breuer J: Detection and characterization of focal liver lesions: a Japanese phase III, multicenter comparison between gadoxetic acid disodium-enhanced magnetic resonance imaging and contrast-enhanced computed tomography predominantly in patients with hepatocellular carcinoma and chronic liver disease. Invest Radiol 2010;45:133-141.

-8 Yoo SH, Choi JY, Jang JW, Bae SH, Yoon SK, Kim DG, Yoo YK, Rha SE, Lee YJ, Jung ES: Gd-EOB-DTPA-enhanced MRI is better than MDCT in decision making of curative treatment for hepatocellular carcinoma. Ann Surg Oncol 2013;20:2893-2900.

-9 Chen CZ, Rao SX, Ding Y, Zhang SJ, Li F, Gao Q, Zeng MS: Hepatocellular carcinoma 20 mm or smaller in cirrhosis patients: earlymagneticresonance enhancementby gadoxeticacid compared withgadopentetate dimeglumine. Hepatol Int 2014;8:104-111.

10 Joo I, Lee JM: Recent advances in the imaging diagnosis of hepatocellular carcinoma: value of gadoxetic acidenhanced MRI. Liver Cancer 2016;5:67-87.

11 Chen BB, Murakami T, Shih TT, Sakamoto M, Matsui O, Choi BI, Kim MJ, Lee JM, Yang RJ, Zeng MS, Chen RC, Liang JD: Novel imaging diagnosis for hepatocellular carcinoma: consensus from the 5 th Asia-Pacific Primary Liver Cancer Expert Meeting (APPLE 2014). Liver Cancer 2015;4:215-227.

12 Merkle EM, Zech CJ, Bartolozzi C, Bashir MR, Ba-Ssalamah A, Huppertz A, Lee JM, Ricke J, Sakamoto M, Sirlin CB, Ye SL, Zeng M: Consensus report from the 7th International Forum for Liver Magnetic Resonance Imaging. Eur Radiol 2016;26:674-682.

-13 Boellaard R, Delgado-Bolton R, Oyen WJ, Giammarile F, Tatsch K, Eschner W, Verzijlbergen FJ, Barrington SF, Pike LC, Weber WA, Stroobants S, Delbeke D, Donohoe KJ, Holbrook S, Graham MM, Testanera G, Hoekstra OS, Zijlstra J, Visser E, Hoekstra CJ, Pruim J, Willemsen A, Arends B, Kotzerke J, Bockisch A, Beyer T, Chiti A, Krause BJ; European Association of Nuclear Medicine: FDG PET/CT: EANM procedure guidelines for tumour imaging: version 2.0. Eur J Nucl Med Mol Imaging 2015;42:328-354. 
Zhou et al.: 2017 Liver Cancer Guidelines in China

14 Boellaard R, O’Doherty MJ, Weber WA, Mottaghy FM, Lonsdale MN, Stroobants SG, Oyen WJ, Kotzerke J, Hoekstra OS, Pruim J, Marsden PK, Tatsch K, Hoekstra CJ, Visser EP, Arends B, Verzijlbergen FJ, Zijlstra JM, Comans EF, Lammertsma AA, Paans AM, Willemsen AT, Beyer T, Bockisch A, Schaefer-Prokop C, Delbeke D, Baum RP, Chiti A, Krause BJ: FDG PET and PET/CT: EANM procedure guidelines for tumour PET imaging: version 1.0. Eur J Nucl Med Mol Imaging 2010;37:181-200.

15 Ferda J, Ferdova E, Baxa J, Kreuzberg B, Daum 0, Treska V, Skalicky T: The role of 18F-FDG accumulation and arterial enhancement as biomarkers in the assessment of typing, grading and staging of hepatocellular carcinoma using 18F-FDG-PET/CT with integrated dual-phase CT angiography. Anticancer Res 2015;35: 2241-2246.

16 Lee JW, Oh JK, Chung YA, Na SJ, Hyun SH, Hong IK, Eo JS, Song BI, Kim TS, Kim do Y, Kim SU, Moon DH, Lee JD, Yun M: Prognostic significance of 18F-FDG uptake in hepatocellular carcinoma treated with transarterial chemoembolization or concurrent chemoradiotherapy: a multicenter retrospective cohort study. J Nucl Med 2016;57:509-516.

17 Hyun SH, Eo JS, Lee JW, Choi JY, Lee KH, Na SJ, Hong IK, Oh JK, Chung YA, Song BI, Kim TS, Kim KS, Moon DH, Yun M: Prognostic value of 18F-fluorodeoxyglucose positron emission tomography/computed tomography in patients with Barcelona Clinic Liver Cancer stages 0 and A hepatocellular carcinomas: a multicenter retrospective cohort study. Eur J Nucl Med Mol Imaging, Epub ahead of print.

18 Park JW, Kim JH, Kim SK, Kang KW, Park KW, Choi JI, Lee WJ, Kim CM, Nam BH: A prospective evaluation of 18F-FDG and 11C-acetate PET/CT for detection of primary and metastatic hepatocellular carcinoma. J Nucl Med 2008;49:1912-1921.

19 Lin CY, Chen JH, Liang JA, Lin CC, Jeng LB, Kao CH: 18F-FDG PET or PET/CT for detecting extrahepatic metastases or recurrent hepatocellular carcinoma: a systematic review and meta-analysis. Eur J Radiol 2012;81: 2417-2422.

20 Wahl RL, Jacene H, Kasamon Y, Lodge MA: From RECIST to PERCIST: Evolving considerations for PET response criteria in solid tumors. J Nucl Med 2009;50(suppl 1):122S-150S.

-21 Chalian H, Tore HG, Horowitz JM, Salem R, Miller FH, Yaghmai V: Radiologic assessment of response to therapy: comparison of RECIST Versions 1.1 and 1.0. Radiographics 2011;31:2093-2105.

22 Zhang Y, Shi H, Li B, Cai L, Gu Y, Xiu Y: The added value of SPECT/spiral CT in patients with equivocal bony metastasis from hepatocellular carcinoma. Nuklearmedizin 2015;54:255-261.

-23 Forner A, Vilana R, Ayuso C, Bianchi L, Sole M, Ayuso JR, Boix L, Sala M, Varela M, Llovet JM, Bru C, Bruix J: Diagnosis of hepatic nodules $20 \mathrm{~mm}$ or smaller in cirrhosis: prospective validation of the noninvasive diagnostic criteria for hepatocellular carcinoma. Hepatology 2008;47:97-104.

24 Nara S, Shimada K, Sakamoto Y, Esaki M, Kishi Y, Kosuge T, Ojima H: Prognostic impact of marginal resection for patients with solitary hepatocellular carcinoma: evidence from 570 hepatectomies. Surgery 2012;151: 526-536.

25 Bass BP, Engel KB, Greytak SR, Moore HM: A review of preanalytical factors affecting molecular, protein, and morphological analysis of formalin-fixed, paraffin-embedded (FFPE) tissue: how well do you know your FFPE specimen? Arch Pathol Lab Med 2014;138:1520-1530.

26 Westra WH, Hruban RH, Phelps TH, Isacson C: Surgical Pathology Dissection: An Illustrated Guide. New York, Springer, 2003.

-27 Lu XY, Xi T, Lau WY, Dong H, Zhu Z, Shen F, Wu MC, Cong WM: Hepatocellular carcinoma expressing cholangiocyte phenotype is a novel subtype with highly aggressive behavior. Ann Surg Oncol 2011;18:2210-2217.

-28 Cong WM, Bu H, Chen J, et al: Practice guidelines for the pathological diagnosis of primary liver cancer: 2015 update. World J Gastroenterol 2016;22:9279-9287.

29 Scheuer PJ: Classification of chronic viral hepatitis: a need for reassessment. J Hepatol 1991;13:372-374

30 WHO: Guidelines for the Prevention, Care and Treatment of Persons with Chronic Hepatitis B Infection. Geneva, WHO, 2015.

-31 Rodriguez-Peralvarez M, Luong TV, Andreana L, Meyer T, Dhillon AP, Burroughs AK: A systematic review of microvascular invasion in hepatocellular carcinoma: diagnostic and prognostic variability. Ann Surg Oncol 2013;20:325-339.

-32 Eguchi S, Takatsuki M, Hidaka M, Soyama A, Tomonaga T, Muraoka I, Kanematsu T: Predictor for histological microvascular invasion of hepatocellular carcinoma: a lesson from 229 consecutive cases of curative liver resection. World J Surg 2010;34:1034-1038.

-33 Fujita N, Aishima S, Iguchi T, Mano Y, Taketomi A, Shirabe K, Honda H, Tsuneyoshi M, Oda Y: Histologic classification of microscopic portal venous invasion to predict prognosis in hepatocellular carcinoma. Hum Pathol 2011;42:1531-1538.

-34 Iguchi T, Shirabe K, Aishima S, Wang H, Fujita N, Ninomiya M, Yamashita Y, Ikegami T, Uchiyama H, Yoshizumi T, Oda Y, Maehara Y: New pathologic stratification of microvascular invasion in hepatocellular carcinoma: predicting prognosis after living-donor liver transplantation. Transplantation 2015;99:1236-1242.

-35 Imamura H, Seyama Y, Kokudo N, Maema A, Sugawara Y, Sano K, Takayama T, Makuuchi M: One thousand fifty-six hepatectomies without mortality in 8 years. Arch Surg 2003;138:1198-1206; discussion 1206.

-36 Kubota K, Makuuchi M, Kusaka K, Kobayashi T, Miki K, Hasegawa K, Harihara Y, Takayama T: Measurement of liver volume and hepatic functional reserve as a guide to decision-making in resectional surgery for hepatic tumors. Hepatology 1997;26:1176-1181. 


\section{Liver Cancer}

\begin{tabular}{l|l}
\hline Liver Cancer 2018;7:235-260 \\
\hline DOI: 10.1159/000488035 & $\begin{array}{l}\text { (c) 2018 S. Karger AG, Basel } \\
\text { www.karger.com/lic }\end{array}$ \\
\hline
\end{tabular}

Zhou et al.: 2017 Liver Cancer Guidelines in China

-37 Bruix J, Castells A, Bosch J, Feu F, Fuster J, Garcia-Pagan JC, Visa J, Bru C, Rodes J: Surgical resection of hepatocellular carcinoma in cirrhotic patients: prognostic value of preoperative portal pressure. Gastroenterology 1996;111:1018-1022.

-38 Cescon M, Colecchia A, Cucchetti A, Peri E, Montrone L, Ercolani G, Festi D, Pinna AD: Value of transient elastography measured with FibroScan in predicting the outcome of hepatic resection for hepatocellular carcinoma. Ann Surg 2012;256:706-712; discussion 712-703.

-39 Mise Y, Sakamoto Y, Ishizawa T, Kaneko J, Aoki T, Hasegawa K, Sugawara Y, Kokudo N: A worldwide survey of the current daily practice in liver surgery. Liver Cancer 2013;2:55-66.

-40 Liu PH, Hsu CY, Hsia CY, Lee YH, Huang YH, Chiou YY, Lin HC, Huo TI: Surgical resection versus radiofrequency ablation for single hepatocellular carcinoma $</=2 \mathrm{~cm}$ in a propensity score model. Ann Surg 2016;263:538545.

41 Feng K, Yan J, Li X, Xia F, Ma K, Wang S, Bie P, Dong J: A randomized controlled trial of radiofrequency ablation and surgical resection in the treatment of small hepatocellular carcinoma. J Hepatol 2012;57:794-802.

-42 Xu Q, Kobayashi S, Ye X, Meng X: Comparison of hepatic resection and radiofrequency ablation for small hepatocellular carcinoma: a meta-analysis of 16,103 patients. Sci Rep 2014;4:7252.

43 Chen MS, Li JQ, Zheng Y, Guo RP, Liang HH, Zhang YQ, Lin XJ, Lau WY: A prospective randomized trial comparing percutaneous local ablative therapy and partial hepatectomy for small hepatocellular carcinoma. Ann Surg 2006;243:321-328.

-44 Yin L, Li H, Li AJ, Lau WY, Pan ZY, Lai EC, Wu MC, Zhou WP: Partial hepatectomy versus transcatheter arterial chemoembolization for resectable multiple hepatocellular carcinoma beyond Milan Criteria: a RCT. J Hepatol 2014;61:82-88.

45 Torzilli G, Belghiti J, Kokudo N, Takayama T, Capussotti L, Nuzzo G, Vauthey JN, Choti MA, De Santibanes E, Donadon M, Morenghi E, Makuuchi M: A snapshot of the effective indications and results of surgery for hepatocellular carcinoma in tertiary referral centers: is it adherent to the EASL/AASLD recommendations? An observational study of the HCC East-West study group. Ann Surg 2013;257:929-937.

46 Ishizawa T, Hasegawa K, Aoki T, Takahashi M, Inoue Y, Sano K, Imamura H, Sugawara Y, Kokudo N, Makuuchi M: Neither multiple tumors nor portal hypertension are surgical contraindications for hepatocellular carcinoma. Gastroenterology 2008;134:1908-1916.

47 Jiang HT, Cao JY: Impact of laparoscopic versus open hepatectomy on perioperative clinical outcomes of patients with primary hepatic carcinoma. Chin Med Sci J 2015;30:80-83.

48 Tang ZY, Uy YQ, Zhou XD, Ma ZC, Lu JZ, Lin ZY, Liu KD, Ye SL, Yang BH, Wang HW, et al: Cytoreduction and sequential resection for surgically verified unresectable hepatocellular carcinoma: evaluation with analysis of 72 patients. World J Surg 1995;19:784-789.

49 Tang ZY, Yu YQ, Zhou XD, Ma ZC, Yang BH, Lin ZY, Lu JZ, Liu KD, Fan Z, Zeng ZC: Treatment of unresectable primary liver cancer: with reference to cytoreduction and sequential resection. World J Surg 1995;19:47-52.

50 Wakabayashi H, Okada S, Maeba T, Maeta H: Effect of preoperative portal vein embolization on major hepatectomy for advanced-stage hepatocellular carcinomas in injured livers: a preliminary report. Surg Today 1997;27:403-410.

51 Aoki T, Kubota K: Preoperative portal vein embolization for hepatocellular carcinoma: consensus and controversy. World J Hepatol 2016;8:439-445.

52 Ogata S, Belghiti J, Farges O, Varma D, Sibert A, Vilgrain V: Sequential arterial and portal vein embolizations before right hepatectomy in patients with cirrhosis and hepatocellular carcinoma. Br J Surg 2006;93:10911098.

-53 D’Haese JG, Neumann J, Weniger M, Pratschke S, Bjornsson B, Ardiles V, Chapman W, Hernandez-Alejandro R, Soubrane O, Robles-Campos R, Stojanovic M, Dalla Valle R, Chan AC, Coenen M, Guba M, Werner J, Schadde E, Angele MK: Should ALPPS be used for liver resection in intermediate-stage HCC? Ann Surg Oncol 2016;23: 1335-1343.

54 Hong de F, Zhang YB, Peng SY, Huang DS: Percutaneous microwave ablation liver partition and portal vein embolization for rapid liver regeneration: a minimally invasive first step of ALPPS for hepatocellular carcinoma. Ann Surg 2016;264:e1-e2.

55 Liu CL, Fan ST, Lo CM, Tung-Ping Poon R, Wong J: Anterior approach for major right hepatic resection for large hepatocellular carcinoma. Ann Surg 2000;232:25-31.

56 Zhang ZM, Lai EC, Zhang C, Yu HW, Liu Z, Wan BJ, Liu LM, Tian ZH, Deng H, Sun QH, Chen XP: The strategies for treating primary hepatocellular carcinoma with portal vein tumor thrombus. Int J Surg 2015;20:8-16.

57 Fu SY, Lau WY, Li AJ, Yang Y, Pan ZY, Sun YM, Lai EC, Zhou WP, Wu MC: Liver resection under total vascular exclusion with or without preceding Pringle manoeuvre. Br J Surg 2010;97:50-55.

-58 Satoh S, Ikai I, Honda G, Okabe H, Takeyama O, Yamamoto Y, Yamamoto N, Iimuro Y, Shimahara Y, Yamaoka Y: Clinicopathologic evaluation of hepatocellular carcinoma with bile duct thrombi. Surgery 2000;128:779783.

59 Shi HY, Wang SN, Wang SC, Chuang SC, Chen CM, Lee KT: Preoperative transarterial chemoembolization and resection for hepatocellular carcinoma: a nationwide Taiwan database analysis of long-term outcome predictors. J Surg Oncol 2014;109:487-493.

60 Zhou WP, Lai EC, Li AJ, Fu SY, Zhou JP, Pan ZY, Lau WY, Wu MC: A prospective, randomized, controlled trial of preoperative transarterial chemoembolization for resectable large hepatocellular carcinoma. Ann Surg 2009; 249:195-202. 
-61 Yen C, Sharma R, Rimassa L, Arizumi T, Bettinger D, Choo HY, Pressiani T, Burlone ME, Pirisi M, Giordano L: Treatment stage migration maximizes survival outcomes in patients with hepatocellular carcinoma treated with sorafenib: an observational study. Liver Cancer 2017;6:313-324.

-62 Ren ZG, Lin ZY, Xia JL, Ye SL, Ma ZC, Ye QH, Qin LX, Wu ZQ, Fan J, Tang ZY: Postoperative adjuvant arterial chemoembolization improves survival of hepatocellular carcinoma patients with risk factors for residual tumor: a retrospective control study. World J Gastroenterol 2004;10:2791-2794.

-63 Fan J, Zhou J, Wu ZQ, Qiu SJ, Wang XY, Shi YH, Tang ZY: Efficacy of different treatment strategies for hepatocellular carcinoma with portal vein tumor thrombosis. World J Gastroenterol 2005;11:1215-1219.

-64 Mazzaferro V, Romito R, Schiavo M, Mariani L, Camerini T, Bhoori S, Capussotti L, Calise F, Pellicci R, Belli G, Tagger A, Colombo M, Bonino F, Majno P, Llovet JM; HCC Italian Task Force: Prevention of hepatocellular carcinoma recurrence with alpha-interferon after liver resection in HCV cirrhosis. Hepatology 2006;44:15431554.

65 Lo CM, Liu CL, Chan SC, Lam CM, Poon RT, Ng IO, Fan ST, Wong J: A randomized, controlled trial of postoperative adjuvant interferon therapy after resection of hepatocellular carcinoma. Ann Surg 2007;245:831-842.

-66 Sun HC, Tang ZY, Wang L, Qin LX, Ma ZC, Ye QH, Zhang BH, Qian YB, Wu ZQ, Fan J, Zhou XD, Zhou J, Qiu SJ, Shen YF: Postoperative interferon alpha treatment postponed recurrence and improved overall survival in patients after curative resection of HBV-related hepatocellular carcinoma: a randomized clinical trial. J Cancer Res Clin Oncol 2006;132:458-465.

67 Nishiguchi S, Tamori A, Kubo S: Effect of long-term postoperative interferon therapy on intrahepatic recurrence and survival rate after resection of hepatitis $\mathrm{C}$ virus-related hepatocellular carcinoma. Intervirology 2005;48:71-75.

-68 Ji J, Shi J, Budhu A, Yu Z, Forgues M, Roessler S, Ambs S, Chen Y, Meltzer PS, Croce CM, Qin LX, Man K, Lo CM, Lee J, Ng IO, Fan J, Tang ZY, Sun HC, Wang XW: MicroRNA expression, survival, and response to interferon in liver cancer. N Engl J Med 2009;361:1437-1447.

-69 Fan J, Yang GS, Fu ZR, Peng ZH, Xia Q, Peng CH, Qian JM, Zhou J, Xu Y, Qiu SJ, Zhong L, Zhou GW, Zhang JJ: Liver transplantation outcomes in 1,078 hepatocellular carcinoma patients: a multi-center experience in Shanghai, China. J Cancer Res Clin Oncol 2009;135:1403-1412.

70 Zheng SS, Xu X, Wu J, Chen J, Wang WL, Zhang M, Liang TB, Wu LM: Liver transplantation for hepatocellular carcinoma: Hangzhou experiences. Transplantation 2008;85:1726-1732.

71 Li J, Yan LN, Yang J, Chen ZY, Li B, Zeng Y, Wen TF, Zhao JC, Wang WT, Yang JY, Xu MQ, Ma YK: Indicators of prognosis after liver transplantation in Chinese hepatocellular carcinoma patients. World J Gastroenterol 2009;15:4170-4176.

-72 Rodriguez-Peralvarez M, Tsochatzis E, Naveas MC, Pieri G, Garcia-Caparros C, O’Beirne J, Poyato-Gonzalez A, Ferrin-Sanchez G, Montero-Alvarez JL, Patch D, Thorburn D, Briceno J, De la Mata M, Burroughs AK: Reduced exposure to calcineurin inhibitors early after liver transplantation prevents recurrence of hepatocellular carcinoma. J Hepatol 2013;59:1193-1199.

73 Liang W, Wang D, Ling X, Kao AA, Kong Y, Shang Y, Guo Z, He X: Sirolimus-based immunosuppression in liver transplantation for hepatocellular carcinoma: a meta-analysis. Liver Transplant 2012;18:62-69.

74 Zhou J, Wang Z, Wu ZQ, Qiu SJ, Yu Y, Huang XW, Tang ZY, Fan J: Sirolimus-based immunosuppression therapy in liver transplantation for patients with hepatocellular carcinoma exceeding the Milan criteria. Transplant Proc 2008;40:3548-3553.

75 Hasegawa K, Aoki T, Ishizawa T, Kaneko J, Sakamoto Y, Sugawara Y, Kokudo N: Comparison of the therapeutic outcomes between surgical resection and percutaneous ablation for small hepatocellular carcinoma. Ann Surg Oncol 2014;21(suppl 3):S348-S355.

76 Li L, Zhang J, Liu X, Li X, Jiao B, Kang T: Clinical outcomes of radiofrequency ablation and surgical resection for small hepatocellular carcinoma: a meta-analysis. J Gastroenterol Hepatol 2012;27:51-58.

77 Huang J, Yan L, Cheng Z, Wu H, Du L, Wang J, Xu Y, Zeng Y: A randomized trial comparing radiofrequency ablation and surgical resection for HCC conforming to the Milan criteria. Ann Surg 2010;252:903-912.

-78 Peng ZW, Zhang YJ, Chen MS, Xu L, Liang HH, Lin XJ, Guo RP, Zhang YQ, Lau WY: Radiofrequency ablation with or without transcatheter arterial chemoembolization in the treatment of hepatocellular carcinoma: a prospective randomized trial. J Clin Oncol 2013;31:426-432.

79 Morimoto M, Numata K, Kondou M, Nozaki A, Morita S, Tanaka K: Midterm outcomes in patients with intermediate-sized hepatocellular carcinoma: a randomized controlled trial for determining the efficacy of radiofrequency ablation combined with transcatheter arterial chemoembolization. Cancer 2010;116:5452-5460.

80 Pelletier G, Ducreux M, Gay F, Luboinski M, Hagege H, Dao T, Van Steenbergen W, Buffet C, Rougier P, Adler M, Pignon JP, Roche A: Treatment of unresectable hepatocellular carcinoma with lipiodol chemoembolization: a multicenter randomized trial. Groupe CHC. J Hepatol 1998;29:129-134.

81 Di Vece F, Tombesi P, Ermili F, Maraldi C, Sartori S: Coagulation areas produced by cool-tip radiofrequency ablation and microwave ablation using a device to decrease back-heating effects: a prospective pilot study. Cardiovasc Intervent Radiol 2014;37:723-729.

-82 Lencioni R, de Baere T, Soulen MC, Rilling WS, Geschwind JF: Lipiodol transarterial chemoembolization for hepatocellular carcinoma: a systematic review of efficacy and safety data. Hepatology 2016;64:106-116.

83 Lo CM, Ngan H, Tso WK, Liu CL, Lam CM, Poon RT, Fan ST, Wong J: Randomized controlled trial of transarterial lipiodol chemoembolization for unresectable hepatocellular carcinoma. Hepatology 2002;35:1164-1171. 
Zhou et al.: 2017 Liver Cancer Guidelines in China

84 Llovet JM, Real MI, Montana X, Planas R, Coll S, Aponte J, Ayuso C, Sala M, Muchart J, Sola R, Rodes J, Bruix J; Barcelona Liver Cancer Group: Arterial embolisation or chemoembolisation versus symptomatic treatment in patients with unresectable hepatocellular carcinoma: a randomised controlled trial. Lancet 2002;359:17341739.

85 Camma C, Schepis F, Orlando A, Albanese M, Shahied L, Trevisani F, Andreone P, Craxi A, Cottone M: Transarterial chemoembolization for unresectable hepatocellular carcinoma: meta-analysis of randomized controlled trials. Radiology 2002;224:47-54.

86 Llovet JM, Bruix J: Systematic review of randomized trials for unresectable hepatocellular carcinoma: chemoembolization improves survival. Hepatology 2003;37:429-442.

87 Coordination Group IMG, Society of Radiology, Chinese Medical Association: Expert consensus for standard operating procedures for transcatheter arterial chemoembolization for primary hepatocellular carcinoma. Chin J Radiol 2011;45:908-912.

-88 Yang M, Fang Z, Yan Z, Luo J, Liu L, Zhang W, Wu L, Ma J, Yang Q, Liu Q: Transarterial chemoembolisation (TACE) combined with endovascular implantation of an iodine-125 seed strand for the treatment of hepatocellular carcinoma with portal vein tumour thrombosis versus TACE alone: a two-arm, randomised clinical trial. J Cancer Res Clin Oncol 2014;140:211-219.

-89 Song MJ, Chun HJ, Song DS, Kim HY, Yoo SH, Park CH, Bae SH, Choi JY, Chang UI, Yang JM, Lee HG, Yoon SK: Comparative study between doxorubicin-eluting beads and conventional transarterial chemoembolization for treatment of hepatocellular carcinoma. J Hepatol 2012;57:1244-1250.

-90 Lammer J, Malagari K, Vogl T, Pilleul F, Denys A, Watkinson A, Pitton M, Sergent G, Pfammatter T, Terraz S, Benhamou Y, Avajon Y, Gruenberger T, Pomoni M, Langenberger H, Schuchmann M, Dumortier J, Mueller C, Chevallier P, Lencioni R; PRECISION V Study Investigators: Prospective randomized study of doxorubicineluting-bead embolization in the treatment of hepatocellular carcinoma: results of the PRECISION V study. Cardiovasc Intervent Radiol 2010;33:41-52.

91 Golfieri R, Giampalma E, Renzulli M, Cioni R, Bargellini I, Bartolozzi C, Breatta AD, Gandini G, Nani R, Gasparini D, Cucchetti A, Bolondi L, Trevisani F; Precision Italia Study Group: Randomised controlled trial of doxorubicin-eluting beads vs conventional chemoembolisation for hepatocellular carcinoma. Br J Cancer 2014;111: 255-264.

-92 Lee YK, Jung KS, Kim DY, Choi JY, Kim BK, Kim SU, Park JY, Ahn SH, Han KH, Kim GM, Kim MD, Park SI, Won JY, Lee DY: Conventional versus drug-eluting beads chemoembolization for hepatocellular carcinoma: emphasis on the impact of tumor size. J Gastroenterol Hepatol 2017;32:487-496.

93 Geschwind JF, Gholam PM, Goldenberg A, Mantry P, Martin RC, Piperdi B, Zigmont E, Imperial J, Babajanyan S, Foreman PK, Cohn A: Use of transarterial chemoembolization (TACE) and sorafenib in patients with unresectable hepatocellular carcinoma: US regional analysis of the GIDEON Registry. Liver Cancer 2016;5:37-46.

$\$ 94$ Arizumi T, Ueshima K, Minami T, Kono M, Chishina H, Takita M, Kitai S, Inoue T, Yada N, Hagiwara S, Minami Y, Sakurai T, Nishida N, Kudo M: Effectiveness of sorafenib in patients with transcatheter arterial chemoembolization (TACE) refractory and intermediate-stage hepatocellular carcinoma. Liver Cancer 2015;4:253262.

95 Zeng ZC, Tang ZY, Fan J, Zhou J, Qin LX, Ye SL, Sun HC, Wang BL, Yu Y, Wang JH, Guo W: A comparison of chemoembolization combination with and without radiotherapy for unresectable hepatocellular carcinoma. Cancer J 2004;10:307-316.

\$6 Meng MB, Cui YL, Lu Y, She B, Chen Y, Guan YS, Zhang RM: Transcatheter arterial chemoembolization in combination with radiotherapy for unresectable hepatocellular carcinoma: a systematic review and meta-analysis. Radiother Oncol 2009;92:184-194.

-97 Zeng ZC, Fan J, Tang ZY, Zhou J, Qin LX, Wang JH, Sun HC, Wang BL, Zhang JY, Jiang GL, Wang YQ: A comparison of treatment combinations with and without radiotherapy for hepatocellular carcinoma with portal vein and/ or inferior vena cava tumor thrombus. Int J Radiat Oncol Biol Phys 2005;61:432-443.

-98 Yoon HI, Seong J: Optimal selection of radiotherapy as part of a multimodal approach for hepatocellular carcinoma. Liver Cancer 2016;5:139-151.

\$9 Zeng ZC, Tang ZY, Fan J, Qin LX, Ye SL, Zhou J, Sun HC, Wang BL, Wang JH: Consideration of role of radiotherapy for lymph node metastases in patients with HCC: retrospective analysis for prognostic factors from 125 patients. Int J Radiat Oncol Biol Phys 2005;63:1067-1076.

100 Zhou LY, Zeng ZC, Fan J, Chen B, Rao SX, He J, Yang P, Hou JZ, Wu ZF, Zhang JY, Hu Y: Radiotherapy treatment of adrenal gland metastases from hepatocellular carcinoma: clinical features and prognostic factors. BMC Cancer 2014;14:878-887.

101 He J, Zeng ZC, Tang ZY, Fan J, Zhou J, Zeng MS, Wang JH, Sun J, Chen B, Yang P, Pan BS: Clinical features and prognostic factors in patients with bone metastases from hepatocellular carcinoma receiving external beam radiotherapy. Cancer 2009;115:2710-2720.

102 Wang WH, Wang Z, Wu JX, Zhang T, Rong WQ, Wang LM, Jin J, Wang SL, Song YW, Liu YP, Ren H, Fang H, Wang WQ, Liu XF, Yu ZH, Li YX: Survival benefit with IMRT following narrow-margin hepatectomy in patients with hepatocellular carcinoma close to major vessels. Liver Int 2015;35:2603-2610.

103 Wang MH, Ji Y, Zeng ZC, Tang ZY, Fan J, Zhou J, Zeng MS, Bi AH, Tan YS: Impact factors for microinvasion in patients with hepatocellular carcinoma: possible application to the definition of clinical tumor volume. Int J Radiat Oncol Biol Phys 2010;76:467-476. 
104 Dawson LA, Normolle D, Balter JM, McGinn CJ, Lawrence TS, Ten Haken RK: Analysis of radiation-induced liver disease using the Lyman NTCP model. Int J Radiat Oncol Biol Phys 2002;53:810-821.

105 Liang SX, Zhu XD, Xu ZY, Zhu J, Zhao JD, Lu HJ, Yang YL, Chen L, Wang AY, Fu XL, Jiang GL: Radiation-induced liver disease in three-dimensional conformal radiation therapy for primary liver carcinoma: the risk factors and hepatic radiation tolerance. Int J Radiat Oncol Biol Phys 2006;65:426-434.

106 Chon YE, Seong J, Kim BK, Cha J, Kim SU, Park JY, Ahn SH, Han KH, Chon CY, Shin SK, Kim DY: Gastroduodenal complications after concurrent chemoradiation therapy in patients with hepatocellular carcinoma: endoscopic findings and risk factors. Int J Radiat Oncol Biol Phys 2011;81:1343-1351.

107 Hou JZ, Zeng ZC, Wang BL, Yang P, Zhang JY, Mo HF: High dose radiotherapy with image-guided hypo-IMRT for hepatocellular carcinoma with portal vein and/or inferior vena cava tumor thrombi is more feasible and efficacious than conventional 3D-CRT. Jpn J Clin Oncol 2016;46:357-362.

108 Hu Y, Zhou YK, Chen YX, Shi SM, Zeng ZC: 4D-CT scans reveal reduced magnitude of respiratory liver motion achieved by different abdominal compression plate positions in patients with intrahepatic tumors undergoing helical tomotherapy. Med Phys 2016;43:4335.

109 Lau WY, Teoh YL, Win KM, Lee RC, de Villa VH, Kim YH, Liang PC, Santos-Ocampo RS, Lo RH, Lim KB, Tai DW, Ng DC, Irani FG, Gogna A, Chow PK: Current role of selective internal radiation with yttrium-90 in liver tumors. Future Oncol 2016;12:1193-1204.

110 Edeline J, Gilabert M, Garin E, Boucher E, Raoul JL: Yttrium-90 microsphere radioembolization for hepatocellular carcinoma. Liver Cancer 2015;4:16-25.

111 Xu J, Shen ZY, Chen XG, Zhang Q, Bian HJ, Zhu P, Xu HY, Song F, Yang XM, Mi L, Zhao QC, Tian R, Feng Q, Zhang SH, Li Y, Jiang JL, Li L, Yu XL, Zhang Z, Chen ZN: A randomized controlled trial of Licartin for preventing hepatoma recurrence after liver transplantation. Hepatology 2007;45:269-276.

112 Raoul JL, Guyader D, Bretagne JF, Duvauferrier R, Bourguet P, Bekhechi D, Deugnier YM, Gosselin M: Randomized controlled trial for hepatocellular carcinoma with portal vein thrombosis: intra-arterial iodine131-iodized oil versus medical support. J Nucl Med 1994;35:1782-1787.

113 Cucchetti A, Piscaglia F, Pinna AD, Djulbegovic B, Mazzotti F, Bolondi L: Efficacy and safety of systemic therapies for advanced hepatocellular carcinoma: a network meta-analysis of phase III trials. Liver Cancer 2017; 6:337-348.

114 Llovet JM, Ricci S, Mazzaferro V, Hilgard P, Gane E, Blanc JF, de Oliveira AC, Santoro A, Raoul JL, Forner A, Schwartz M, Porta C, Zeuzem S, Bolondi L, Greten TF, Galle PR, Seitz JF, Borbath I, Haussinger D, Giannaris T, Shan M, Moscovici M, Voliotis D, Bruix J; SHARP Investigators Study Group: Sorafenib in advanced hepatocellular carcinoma. N Engl J Med 2008;359:378-390.

115 Pressiani T, Boni C, Rimassa L, Labianca R, Fagiuoli S, Salvagni S, Ferrari D, Cortesi E, Porta C, Mucciarini C, Latini L, Carnaghi C, Banzi M, Fanello S, De Giorgio M, Lutman FR, Torzilli G, Tommasini MA, Ceriani R, Covini G, Tronconi MC, Giordano L, Locopo N, Naimo S, Santoro A: Sorafenib in patients with Child-Pugh class A and B advanced hepatocellular carcinoma: a prospective feasibility analysis. Ann Oncol 2013;24:406-411.

116 Qin S, Bai Y, Lim HY, Thongprasert S, Chao Y, Fan J, Yang TS, Bhudhisawasdi V, Kang WK, Zhou Y, Lee JH, Sun Y: Randomized, multicenter, open-label study of oxaliplatin plus fluorouracil/leucovorin versus doxorubicin as palliative chemotherapy in patients with advanced hepatocellular carcinoma from Asia. J Clin Oncol 2013; 31:3501-3508.

117 Lee JH, Lee JH, Lim YS, Yeon JE, Song TJ, Yu SJ, Gwak GY, Kim KM, Kim YJ, Lee JW, Yoon JH: Adjuvant immunotherapy with autologous cytokine-induced killer cells for hepatocellular carcinoma. Gastroenterology 2015; 148:1383-1391 e1386.

118 Kudo M: Immune checkpoint blockade in hepatocellular carcinoma: 2017 update. Liver Cancer 2016;6:1-12.

119 Xu L, Wang J, Kim Y, Shuang ZY, Zhang YJ, Lao XM, Li YQ, Chen MS, Pawlik TM, Xia JC, Li SP, Lau WY: A randomized controlled trial on patients with or without adjuvant autologous cytokine-induced killer cells after curative resection for hepatocellular carcinoma. Oncoimmunology 2016;5:e1083671.

$\checkmark 120$ Zeeneldin AA, Eid SM, Darweesh AD, Moneer MM, Saadeldin M: Tamoxifen compared to best supportive care in advanced hepatocelluar carcinoma: a retrospective matched-cohort study. J Egypt Natl Cancer Inst 2014; 26:1-7.

121 Sato Y, Watanabe H, Sone M, Onaya H, Sakamoto N, Osuga K, Takahashi M, Arai Y; Japan Interventional Radiology in Oncology Study Group JIVROSG: Tumor response evaluation criteria for HCC (hepatocellular carcinoma) treated using TACE (transcatheter arterial chemoembolization): RECIST (response evaluation criteria in solid tumors) version 1.1 and mRECIST (modified RECIST): JIVROSG-0602. Ups J Med Sci 2013;118: $16-22$.

122 Wolchok JD, Hoos A, O’Day S, Weber JS, Hamid O, Lebbe C, Maio M, Binder M, Bohnsack O, Nichol G, Humphrey R, Hodi FS: Guidelines for the evaluation of immune therapy activity in solid tumors: immune-related response criteria. Clin Cancer Res 2009;15:7412-7420.

123 Yin J, Li N, Han Y, Xue J, Deng Y, Shi J, Guo W, Zhang H, Wang H, Cheng S, Cao G: Effect of antiviral treatment with nucleotide/nucleoside analogs on postoperative prognosis of hepatitis B virus-related hepatocellular carcinoma: a two-stage longitudinal clinical study. J Clin Oncol 2013;31:3647-3655.

124 Huang G, Lau WY, Wang ZG, Pan ZY, Yuan SX, Shen F, Zhou WP, Wu MC: Antiviral therapy improves postoperative survival in patients with hepatocellular carcinoma: a randomized controlled trial. Ann Surg 2015;261: $56-66$. 